Florida International University FIU Digital Commons

\title{
Zoroastrianism, Cosmology, and Chaos: A Detailed Analysis of the Musical Composition, Druj Aeterni
}

Andrew T. Trelease

Florida International University, atrel005@fiu.edu

DOI: $10.25148 /$ etd.FI13042209

Follow this and additional works at: https://digitalcommons.fiu.edu/etd

\section{Recommended Citation}

Trelease, Andrew T., "Zoroastrianism, Cosmology, and Chaos: A Detailed Analysis of the Musical Composition, Druj Aeterni" (2013). FIU Electronic Theses and Dissertations. 836.

https://digitalcommons.fiu.edu/etd/836 


\section{ABSTRACT OF THE THESIS \\ ZOROASTRIANISM, COSMOLOGY, AND CHAOS: A DETAILED ANALYSIS OF THE MUSICAL COMPOSITION, DRUJ AETERNI \\ by}

Andrew T. Trelease

Florida International University, 2013

Miami, Florida

Professor Orlando Jacinto Garcia, Major Professor

Druj Aeterni is a large chamber ensemble piece for flute, clarinet, French horn, two trumpets, piano, two percussionists, string quintet, and electric bass. My composition integrates three intellectual pursuits and interests, ancient mythology, cosmology, and mathematics. The title of the piece uses Latin and the language of the Avesta, the holy book of Zoroastrianism, and comments upon a philosophical perspective based in string theory. I abstract the cosmological implications of string theory, apply them to the terminology and theology of Zoroastrianism, and then structure the composition in consideration of a possible reconciliation. The analysis that follows incorporates analytical techniques similar to David Cope's style of Vectoral Analysis. 


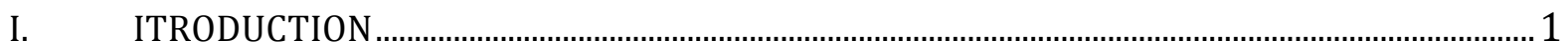

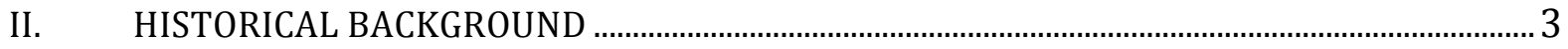

III. STRUCTURAL TECHNIQUES.............................................................................................

IV. ORCHESTRATION TECHNIQUES ……………………................................................19

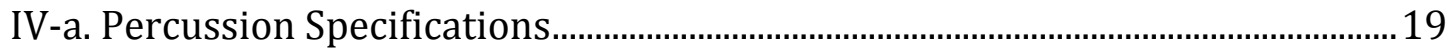

IV-b. The Flexatones …………………………………………………………………..22

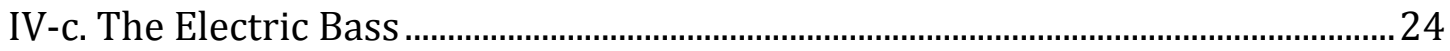

IV-d. Other Instruments ............................................................................................2

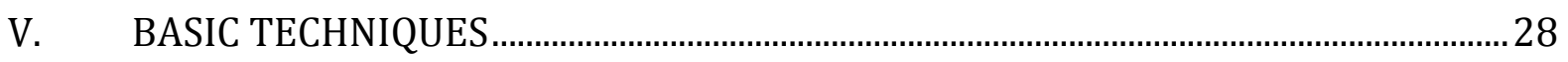

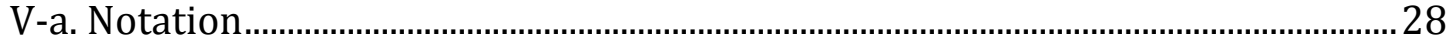

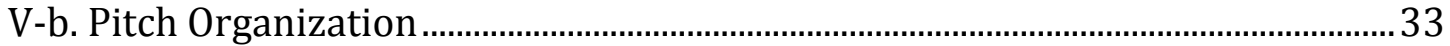

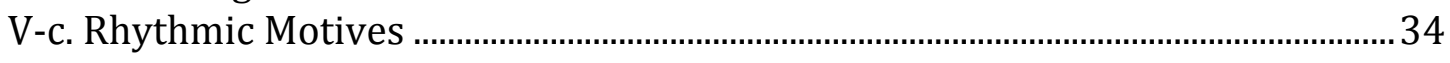

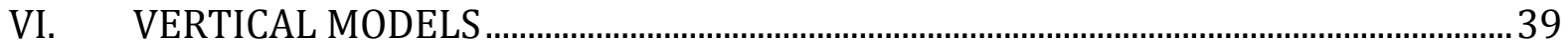

VII. HORIZONTAL MODELS.............................................................................................. 42

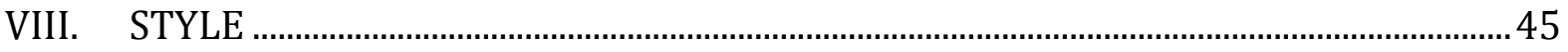

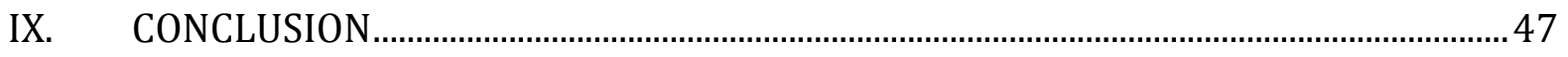

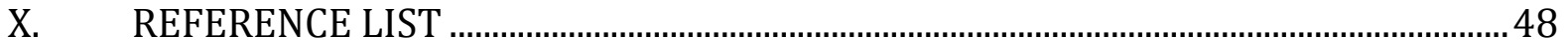

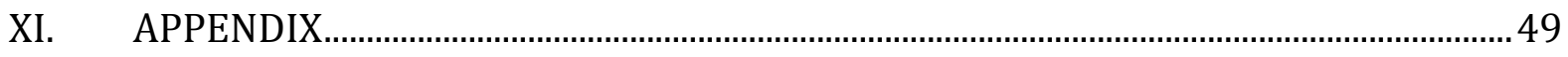




\section{INTRODUCTION}

Druj Aeterni is a large chamber ensemble piece that I composed over the course of six months, beginning in August 2012. Upon completion, the piece was the largest in scale and longest in duration of all my instrumental works. Two composers deeply influenced my style of composition: the Italian composer, Giacinto Scelsi, and the Polish composer, Krzysztof Penderecki. The Style section of this paper explores these influences further. The topic of the composition arises from my interest in religious texts, particularly the Christian Bible.

While I profess no religious faith, my brother serves as an Evangelical Christian Missionary in Turkey. Our close relationship has given me a heightened awareness of the New Testament and its preachments. One interesting characteristic of the New Testament is that it includes several accounts of the same important event. There are similarities between accounts, but the differences are often more revealing.

Specifically, in the second chapter of the Gospel of Matthew (Matthew 2:2), the author states "there came wise men from the east to Jerusalem, saying, Where is he that is born King of the Jews? for we have seen his star in the east, and are come to worship him." The phrase "wise men" is uniquely striking because it does not appear in any of the other Gospels. In place of the phrase "wise men," the original Greek text of Matthew contains the word "magoi." Likewise, the word "magi" appears in the fourth-century Vulgate translation (Matthew 2:2).

One logical question that follows is, "What are magi?" The Gospel of Matthew immediately provides some insight with the words "from the east," implying that the 
magi came from a distinct foreign location somewhere east of Jerusalem. Herodotus, the famous Greek historian, mentions "Magi of Media" several times in his masterpiece, The Histories (Heredotus 1987: 98, 234-247). In Book One, Herodotus remarks upon the unique Magian ritual of delaying the burial of the deceased, first allowing the birds and dogs to drag and tear the corpse. Herodotus contrasts this ritual and others with those of Egyptian priests, implying that the Magi of Media are a priestly caste akin to those of the Egyptians.

The Medes briefly ruled the ancient lands of present-day western Iran, under the kingdom of Astyages, from the Seventh Century BCE to 550 BCE. During the reign of King Cyrus, the Persian Empire conquered the Median Empire and incorporated many of the Medes' religious principles and practices (Dhalla 1972: 67-71). Medians practiced a religion called Zoroastrianism, founded by the prophet Zoroaster, and this theology remained popular in the region well into the third century ACE. Some startling implications arise in relation to the Gospel of Matthew. Since what was once Media sits directly east of Jerusalem, and since contemporaries referred to the Median priests as Magi, one logically assumes that Matthew must have been referring to the priestly Zoroastrians, i.e., Magi. One might be inclined to study Zoroastrianism further after asking, "Why would one religious authority (that of Christianity) attempt to legitimize the divinity of its savior by claiming that His birth was foretold and adored by priests of a foreign religion (the Magi of Zoroastrianism)?" This question inspired me to study Zoroastrianism more closely, which eventually compelled me to incorporate some of the religion's tenets into my music. This paper analyzes both the conceptual and the more literal connections between Zoroastrianism and Druj Aeterni. 


\section{HISTORICAL BACKGROUND}

Druj originates from the ancient religion of Zoroastrianism (Dhalla 1972: 50). The religion was widely practiced by the inhabitants of what is now Iran between 1000 BCE and 300 ACE (Nigosian 1993: 25). Zoroastrianism posits that one Supreme Being, Ahura Mazda, is the creator and essence of the Universe (Nigosian 1993: 71). "Ahura Mazda" approximately translates to “The Wise Lord.” According to Dhalla (1972: 19), The Yasna, one of the holy texts of Zoroastrianism, describes Ahura Mazda as the "apex among the celestial beings... He is not begotten, nor is there one like unto him. Beyond Him, apart from Him, and without Him, nothing exists." To some, this implies that Zoroastrianism is a monotheistic religion that long predates the two most popular monotheistic religions of the present day, Christianity and Islam.

The Yasna is one book within a collection of sacred Zoroastrian texts collectively known as the Avesta. According to the Avesta, Ahura Mazda chose the prophet named Zoroaster (also called Zarathushtra) to spread His message to mankind. The exact date of this occurrence is unknown, but scholars' estimates range from 1000 BCE to the fifth century BCE (Dhalla 1972: 11). While the history and chronology of Zoroaster's life remain enigmatic, some of his theology survives. According to Ardeshir (1952: 76), Zoroaster regarded his faith as a universal religion and considered it "the best for all the living..."

In addition to the Supreme Being, Ahura Mazda, Zoroaster believed in a group of six spiritual beings that he referred to as Amesha Spenta. Amesha Spenta translates to "Immortal Holy One(s)," and one might liken their role in Zoroastrianism to that of the 
archangel in Catholicism (Dhalla 1972: 26). Ahura Mazda and the six Amesha Spenta form the holy heptad. Each of the six Amesha Spenta bears a unique title pertaining to some abstract value that it personifies. Later, as the Zoroastrian faith evolved, six unique elements of creation came to accompany the six abstract values (Rose 2011: 2829). For example, the Amesha Spenta named "Ameretat" represents longevity, and his element of creation is plant life. In summation, there exist six immortal holy spirits and one Supreme Being, but what are their relationships with mankind?

Ahura Mazda and the six Amesha Spenta propagate the positive force that flows within the Universe, known to Zoroastrians as asha. Zoroastrians see the Universe as an epic struggle between the force of asha and the repelling force of druj. The conflict is similar to that of good versus evil within Christian Theology. The connotations of asha and $d r u j$, however, go much deeper than the two subjective values of good and evil. Concepts similar to asha long predate Zoroaster, going back to an old tradition in which followers worshipped three separate Ahura beings, before Zoroaster declared that Ahura Mazda is the one uncreated Creator (Boyce 1979: 19). Asha encompasses the meanings of words like "truth," "order," "righteousness," and "justice." Druj is the repelling force of $a s h a$; therefore $d r u j$ means "chaos," "disorder," and "lies." Like the adversarial Devil of the Bible, Ahriman opposes Ahura Mazda and the six Amesha Spenta. Ahriman, however, does not directly corrupt our cosmos; he works through a subsidiary agent called Angra Mainyu (Nigosian 1993: 85). The relationship between the omniscient creator, Ahura Mazda, and the six lesser Amesha Spenta has its negative mirror image in that between the malevolent lord Ahriman and the subsidiary demon Angra Mainyu. Unlike Christianity, though, Zoroastrianism posits that the adversary, 
Ahriman, originates in a realm outside of our cosmos. Therefore, when Ahura Mazda created our cosmos or realm, the all-wise and all-good Lord did not create evil.

Evil originates in Ahriman, who rushed to thwart and corrupt Ahura Mazda's creation. Since Ahriman exists in a separate realm, he can corrupt our cosmos only through his representative agent, Angra Mainyu. To Zoroastrians, Angra Mainyu is the corrupting force within our cosmos, the wicked advocate of $d r u j$. The conflict between the holy heptad (asha) and Angra Mainyu (druj) pervades the cosmos. Today, we might interpret the conflict to pervade the motion of the tiniest particle to the formation of stars, galaxies, and black holes.

Human beings play a vital role in promulgating ashsa or druj through their words, thoughts, and deeds. Since the ancient Zoroastrians most certainly did not know about the existence of tiny particles, huge galaxies, and endless black holes, and since religious philosophies usually seeks to modify human behavior, Zoroastrians emphasized the role of humans in the struggle between asha and druj. It is interesting, though, to inerpret the concept of a universal struggle between order ( $a$ sh $a$ ) and chaos (druj) in light of modern physics, astronomy, and cosmology.

Some modern physicists, such as Brian Greene, propose that the observable Universe is like a bubble - a bubble that floats in a vast foamy ocean of innumerable bubbles. ${ }^{1}$ This proposed picture of reality suggests that our observable Universe lies

\footnotetext{
${ }^{1}$ Brian Greene, "The Mystery of the Multiverse," Newsweek 159, no. 22 (May 28, 2012): 23. "Pioneers of the subject anticipated that string theory's rigid mathematical architecture would soon yield a single set of definitive, testable predictions. But as the years passed, detailed analysis of the theory's equations revealed numerous solutions, each representing a different possible universe. And numerous means numerous. Today, the tally of possible universes stands at the almost incomprehensible $10^{500}$, a number so large it defies analogy."
} 
within an incomprehensibly large array of universes, each instantiating one of perhaps infinitely many possibilities. Within an infinitude of possibilities exists the particular possibility of our Universe - one seemingly "fine-tuned" for galaxies, stars, planets, life, and humans. Or perhaps put more abstractly, the infinitude of chaos (i.e., the chaotic bubble array of innumerable universes) necessarily encompasses pockets of order (i.e., our life-supporting Universe). Borrowing terms from Zoroastrianism, one might say that within the infinitude of $d r u j$, there exist pockets of asha. The order or asha, however, only appears to be so on a local, observable scale, i.e. it is illusionary. This perspective, which I hold, serves as a unifying compositional element in the piece Druj Aeterni. The title of the piece includes the Latin word Aeterni ("eternity") in the genitive case, implying origin or possession. Thus, one can approximately translate the title to "Eternal Chaos" or "Eternity's Chaos." The piece is a musical interpretation of the Zoroastrian heptad and its adversary, Angra Mainyu, and a sort of commentary with respect to the perspective that all order is some subset of a much broader chaos. 


\section{STRUCTURAL TECHNIQUES}

Druj Aeterni consists of eight sections, the first corresponding to a musical interpretation of Ahura Mazda, followed by six of the Amesha Spenta, and a final section to Angra Mainyu, the advocate of $d r u j$. The qualities of the six Amesha Spenta serve as a section-by-section map for orchestration and timbral organization. Orchestration and timbre are, therefore, inseparable from the overall structure of the piece. Section one relates to the following seven; so sections two through seven will be discussed first, then the last section, and finally the first section. Figure 1 in the appendix outlines the overall form of the piece and provides brief descriptions of each section. The reader may wish to refer to Figure 1 while reading this chapter.

The Amesha Spenta called "Haurvatat" inspired the second section of the piece. Haurvatat embodies the abstract values of wholeness, perfection, and fulfillment at the end of man's life. Zoroastrians ascribe the creation of water to Haurvatat (Dhalla 1972: 39-41). In the score of Druj Aeterni, mm. 32-41 mark the transition between the first section and the Haurvatat section. I introduce the sonorous event of tremolo strings to represent the flowing motion of water. In measure 58, shown in Example 1, the densest layering of tremolo strings occurs. 


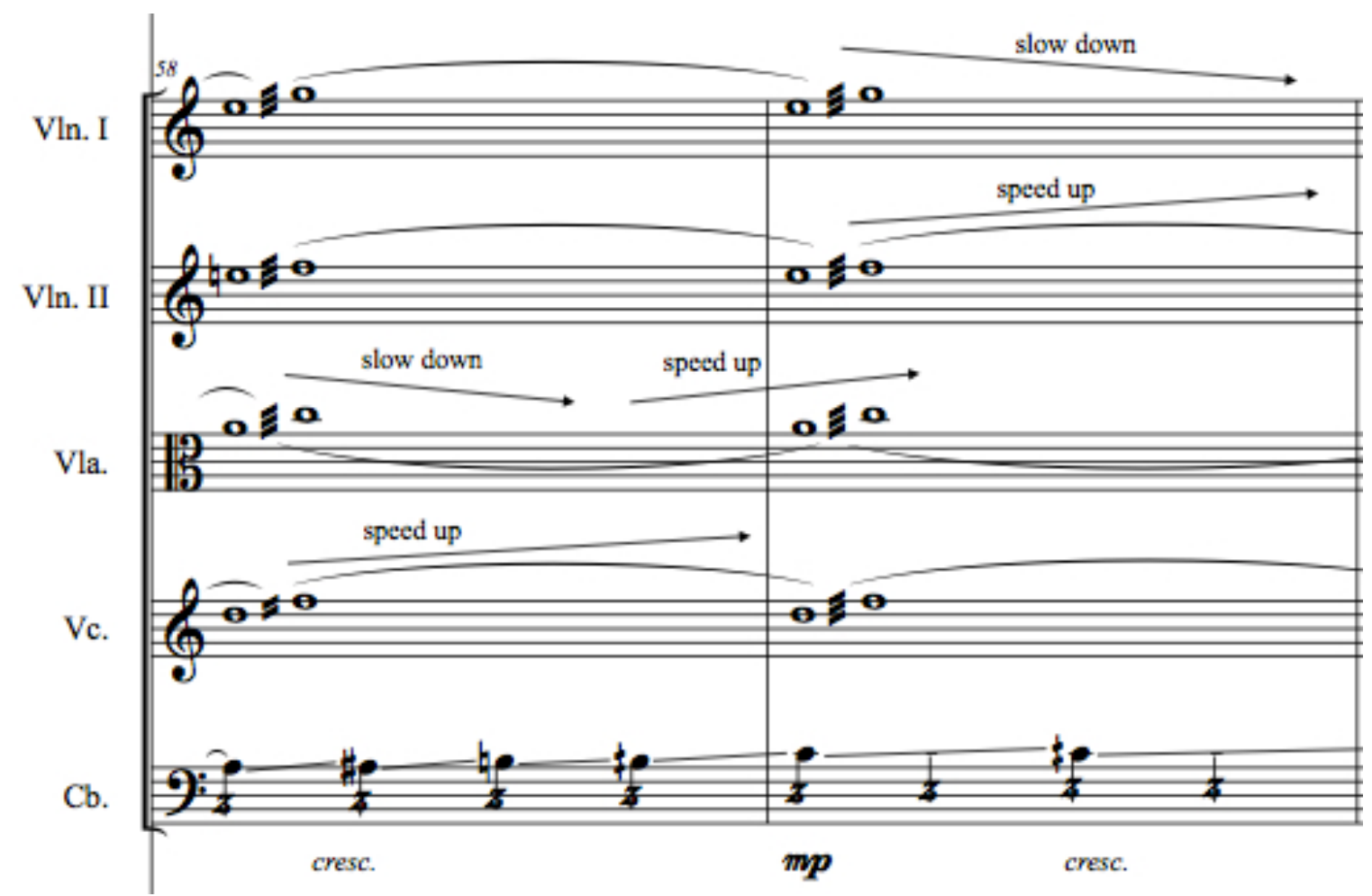

Example 1 - This shows an excerpt from the dense layering technique used in the string parts during the interpretation of Haurvatat.

This layering begins in m. 35 and extends to m. 60. As the layering elapses, each individual string player gradually ascends in pitch, culminating in the very ethereal and glassy texture of m. 65. Here, the violin I, violin II, and viola players sustain notes over two octaves higher than middle $C$ (G, $A$, and $D^{\#}$ respectively). In mm. 60-61 there is a brief transition from tremolo technique to a focus on vibrato, which intensifies and culminates in m. 65 as well. Vibrato adds a shimmering quality to the already bright sound of the high strings. Long ascending layers of tremolo and intensifying vibrato instill in the listener a sense of ascension, representing the abstract values of fulfillment and wholeness.

In mm. 38-43 and 51-57, the music reinforces the tremolo references to flowing water by including rhythmic passages in the piano part. In these measures, the piano 
player depresses the damper pedal so that four, five, and sometimes six separate tones blend and flow through one another. In Example 2, one can see the rhythmic passages of mm. 51-52. This sonority alludes to the malleable qualities of flowing water, the creation of Haurvatat.

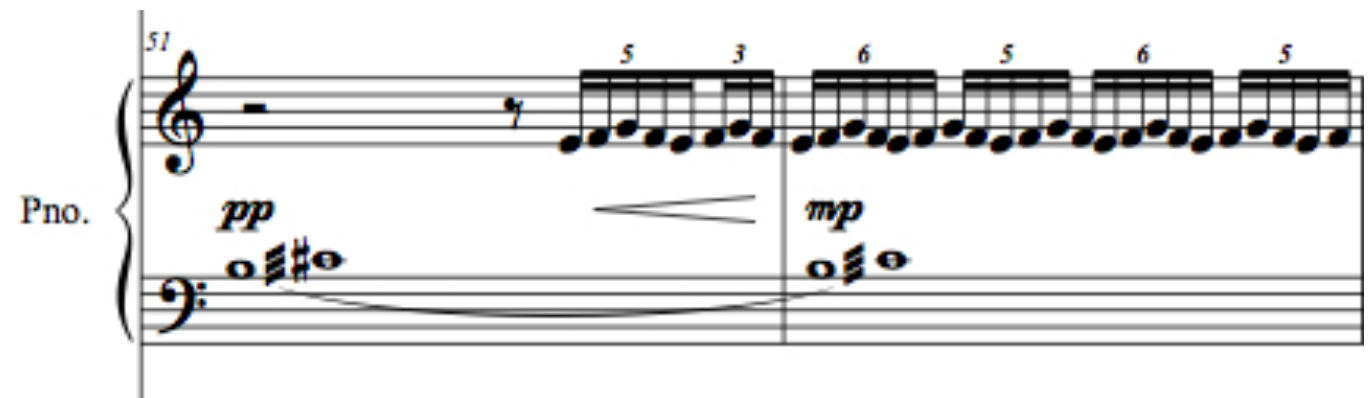

Example 2 - This rhythmic piano passage alternates between pentuplets and sextuplets, reducing the listener's sense of a steady pulse.

Traditionally, Zoroastrians regard Haurvatat and Ameretat as a closely linked duo (Dhalla 1972: 95). The writings within the Avesta often mention both spirits together rather than individually. Theologically, the two together reward the pious after death. Zoroastrians associate Ameretat with long life and immortality, and ascribe to it the creation of plant life. The inseparability of Haurvatat and Ameretat reflects upon the dependent relationship between plant life and water. To maintain a musical link analogous to the immediately preceding biological relationship, I gradually deconstruct the flowing water-like techniques in the strings and piano parts. In mm. 60-64, the previous tremolo strings transform in instrumentation and timbre, becoming trills in the flute part. The new timbre is less dense and more pure, becoming a single melodic line by m. 65 . 
In the piano part, I reinvent the previous rhythmic passages by calling for glissandi inside the piano (m. 61 and m. 64). With the use of the damper pedal, the glissandi produce dense clusters of tones. Some pitch content of the glissandi clusters relates to the previous rhythmic passages, but the timbre is much brighter and more metallic. In Example 3, one can see the piano part's glissando cluster between D and A in the bottom staff. This glissando includes two tones from Example 2, $\mathrm{C}^{\#}$ and B.

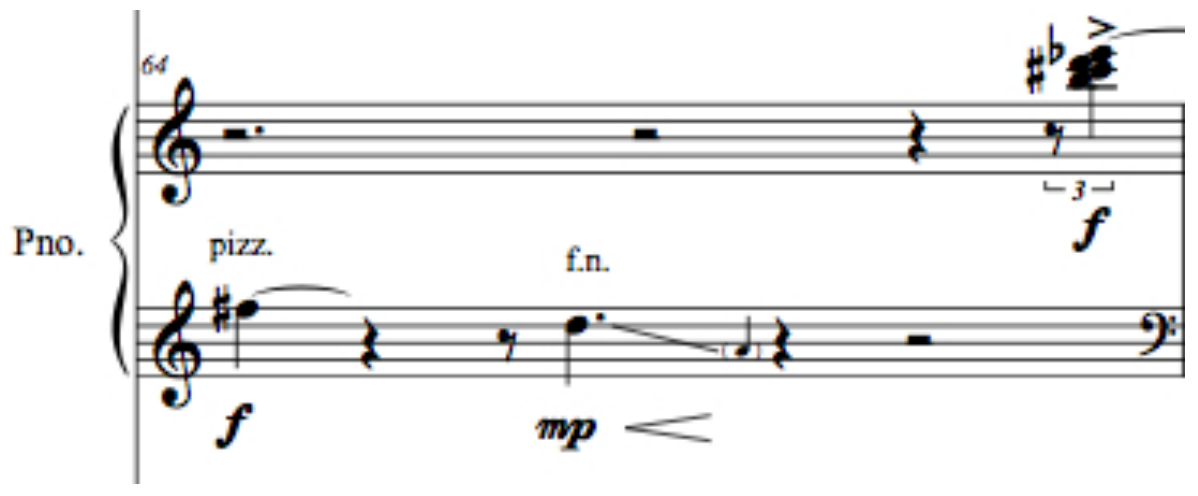

Example 3 - The text "f.n." instructs the piano player to scrape his or her fingernail across the strings that the glissando encompasses.

Parallel to the melodic line of the flute part, I superimpose four melodic lines in the piano part from m. 65 to m. 74. The four lines appear as two, right and left hand, but further analysis yields four conjunctive voices. Example 4 includes mm. 66-71 of the piano part. One can see the four conjunctive voices via the sketch shown in Example 5, which omits the tone cluster found on beat two of measure 67 because the cluster is not structurally part of any one voice. 


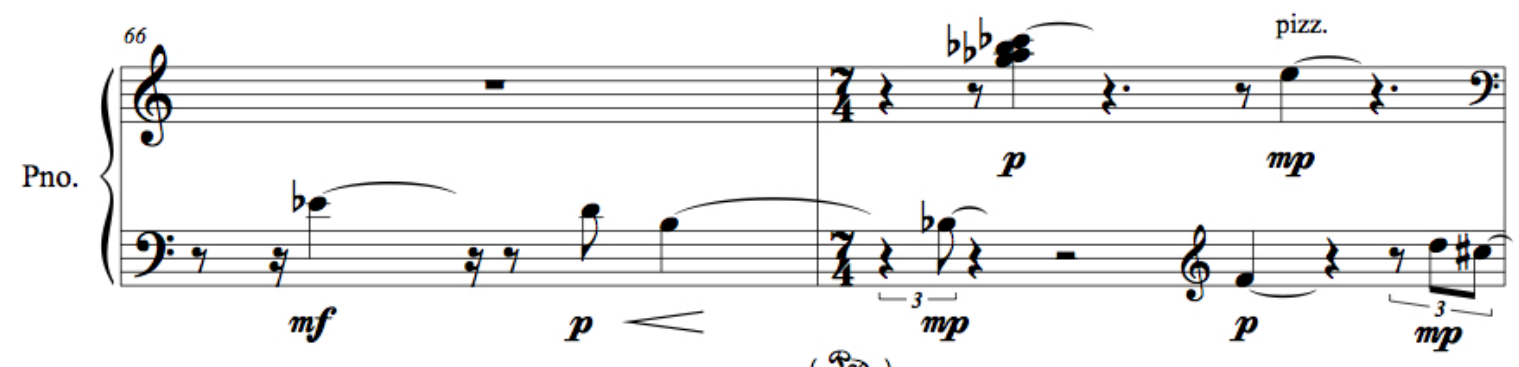

( 200.$)$
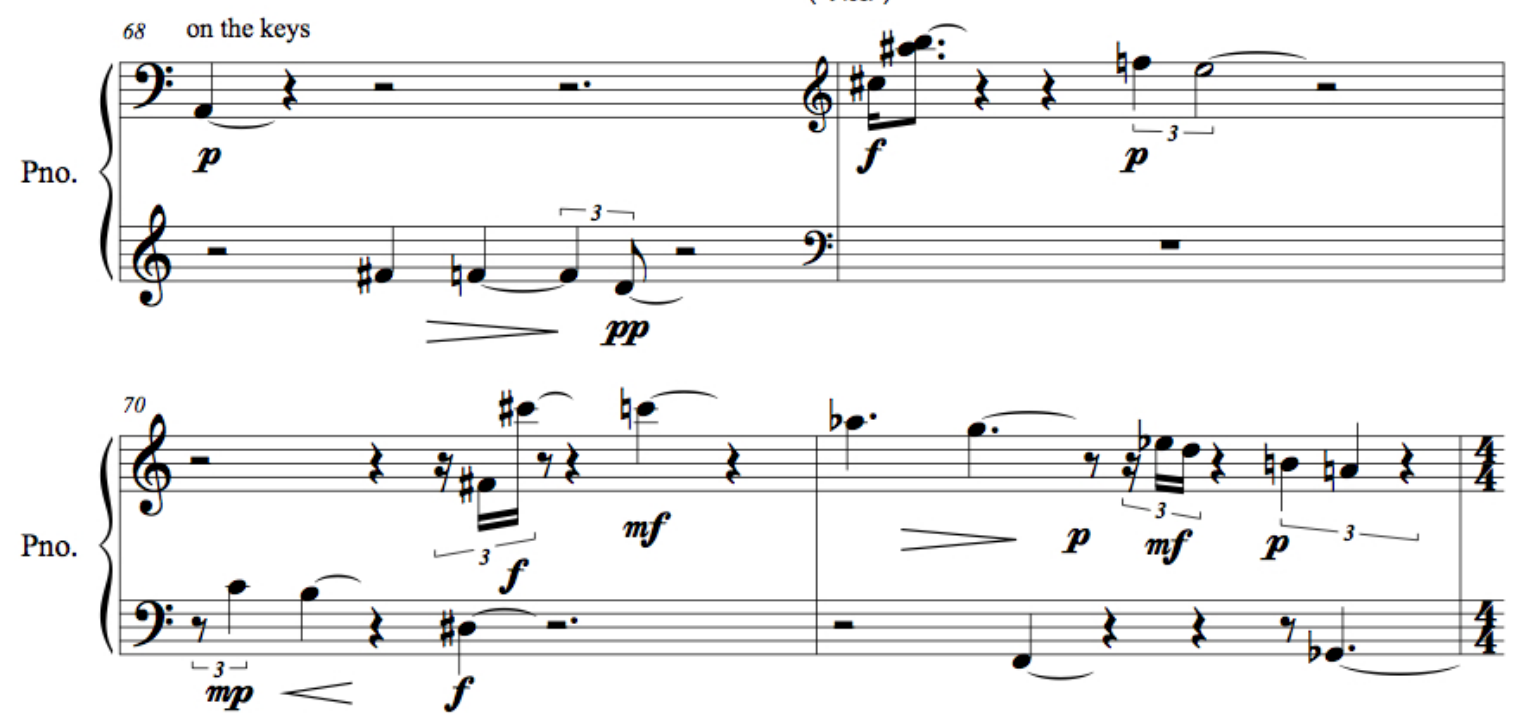

Example 4 - This excerpt shows the final realization of the conjunctive voices, as they appear in the score. In my original sketches, there are four voices in SATB style.

As one can see in Example 4 and Example 5, four melodic voices surface from the two written lines. The pitch material comes from the compositional deconstruction of the dense previous section, Haurvatat. This emulates the idea of water, Haurvatat's creation, providing the nourishment from which plants, Ameretat's creation, grow. 

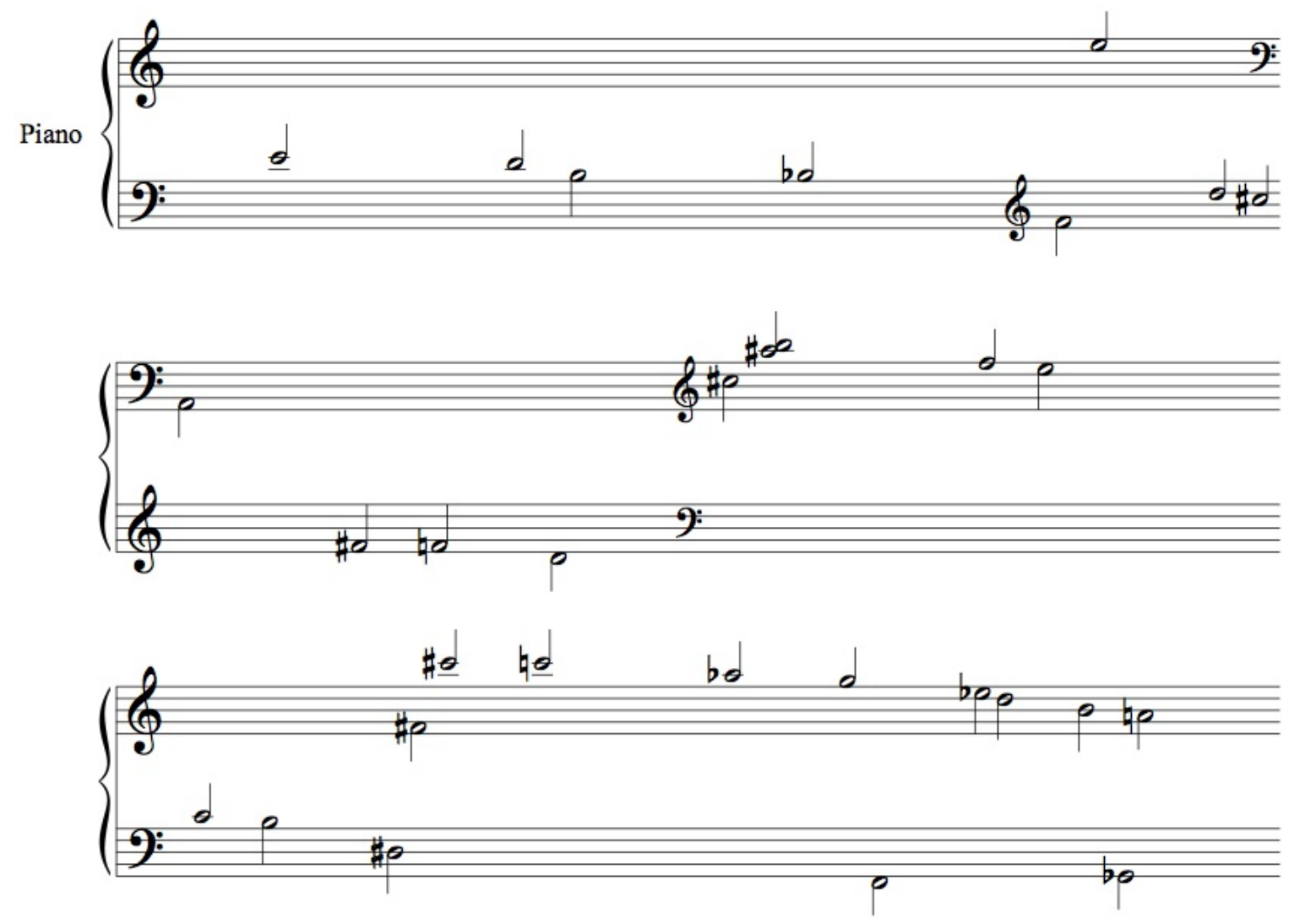

Example 5 - This example displays the content of my original sketches, in SATB style. The open note-heads are not meant to suggest any duration of time, nor are the stems. The stems indicate to which of the four voices each note belongs.

The next section, beginning in m. 75, refers to the Amesha Spenta called Spenta Armaiti, which Nigosian (1993: 78-79) and Boyce (1979: 22) translate as "Holy Devotion." Spenta Armaiti is the spiritual paragon of piety, guiding and protecting devout believers. Zoroastrians believe that Spenta Armaiti is the guardian of Earth, or Earth's mother. To give the listener an immediate sense of devout and majestic guardianship, I abruptly contrast this section from the previous ones by predominantly utilizing the brass. The opening motive, an ascending widely spaced triad followed by a narrower two-note descent, is a condensed variation on the melodic lines of the 
previous section. Also, the motive provides a point of departure and development through fragmentation, elongation, and other techniques (see V-c. Rhythmic Motives). Brass instruments possess a powerful psychological association; we tend to associate the sound with royalty and majesty. Perhaps this stems from the tradition of announcing the presence of royalty with horns or trumpets, or from the purity of the instrument's timbre combined with its shear volume. Regardless of the association's origin, the music alludes to majesty by employing instrumentation replete with brass. This Spenta Armaiti section requires the trumpets players to remove their mutes (senza sordini). This gives the brass a more pure and majestic sound, but also allows for a more appropriate balance of dynamics during the other sections of the piece. In the previous sections, the more distorted and metallic timbre of trumpets with Harmon mutes hints at the section immediately subsequent to the Spenta Armaiti section.

In mm. 85 and 86, the percussion right — "right" refers to the spatial positioning — part includes a brief gesture on the large bass flexatone (see the Orchestration Techniques below for a detailed explanation of the flexatone). This sound is very distinctive can only be replicated with similar large sheets of metal. The unique metallic sound foreshadows the coming section, Khshathra Vairya. According to Dhalla (1972: 94), Khshathra Vairya translates to "Desirable Kingdom," in reference to sovereignty and the wealth of earthly riches. In that regard, Khshathra Vairya somewhat resembles the majesty of Spenta Armaiti. I establish a sonic link between the two sections through the use of brass. In the concrete domain, Khshathra Vairya manifests metals. As the Spenta Armaiti section unfolds into the Khshathra Vairya 
section, the trumpet players reinsert their Harmon mutes and recall the previous majestic motives, now with a more metallic timbre. From mm. 98-128, I focus on metallic timbre. The instrumentation of this section is mostly percussion made from metal, e.g., cymbals, tenor and bass flexatones (large sheets of metal similar to a thunder sheet), crotales, cowbells, and triangles. In addition to playing the cymbals with different types of mallets, the percussionists often use a metallic object to scrape the surface of the cymbals and intensify its metallic sonority. I also call for plucked piano strings, percussive electric bass sounds, and the raspy, Harmon-muted trumpets. All of these instruments and the percussion, combined with their particular playing techniques, incorporate physical metal and produce a variety of metallic timbre. The music includes the cowbell both because of its pertinence to the metallic instrumentation and its traditional role in alerting farmers of their cattle's location, which alludes to the next section of the piece.

Vohu Manah, the next Amesha Spenta, inspires section six. Zoroastrians ascribed particular importance to Vohu Manah partly because they associated him with the oversight and wellbeing of animals and livestock (Nigosian 1993: 75-76). They sometimes attribute to Vohu Manah specific lordship over cows or cattle (Boyce 1979: 23). It is through this association that the cowbell most clearly links this section's music with the previous section.

Vohu Manah, or "Good Mind," is also important because it is Ahura Mazda's first creation and, therefore, preeminently ranked amongst the Amesha Spenta. Similar to the way in which Zoroastrians view Vohu Manah as the shepherd of animals, they 
consider Vohu Manah a shepherd of the other five Amesha Spenta. Some sacred Zoroastrian texts even assert that the other five spirits exist within Vohu Manah (Dhalla 1972: 89). Compositionally, this hierarchical relationship lends itself to the technique of incorporating musical elements from all other sections into this section.

In mm. 130-132, the trill gestures in the woodwind parts refer to the strings' tremolo layers within the Haurvatat section. In Example 6, one can compare the trill gestures in the flute and clarinet parts to the tremolos found in Example 1. The trill gestures include the pitches $D, C^{\#}, A$, and $B^{b}$. All four of these pitches are found in the previous dense string tremolo section.

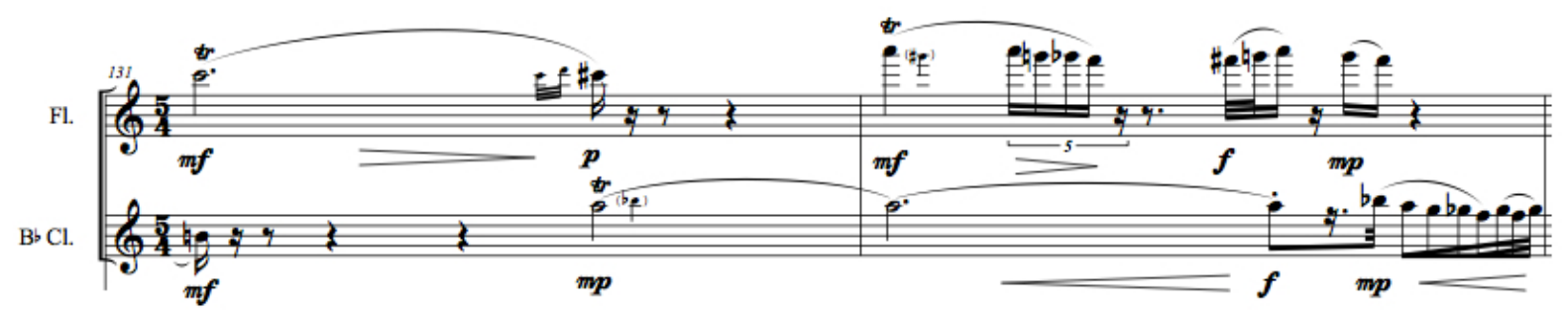

Example 6 - The bold "tr" symbol denotes a trill. All trills rise by step, unless specified otherwise by a parenthetical note.

In $\mathrm{m} .133$ of the clarinet part, and in $\mathrm{m} .137$ of the flute part, the fast flowing $32^{\text {nd }}$ notes are an allusion to the flowing notes of the piano part in $\mathrm{m} .38$ and $\mathrm{m}$. 51. I collapse the melodic lines from the piano part during the Ameretat section (e.g., mm. 70-71), and present them as vertical clusters with tightly spaced intervals in mm. 135, 137, 139, 141, and 144. In mm. 141-147, the continued use of metallic percussion, such as cowbells and cymbals, recalls the neighboring Khshathra Vairya section. The only section that the music does not directly refer to within Vohu Manah is the Spenta Armaiti section. This saves the brass timbre for the final Amesha Spenta, Asha Vahishta. 
Asha Vahishta is perhaps the most abstract of the six Amesha Spenta. The name means "Best Righteousness," implying that this spirit personifies the cosmic order (asha). Asha Vahishta works with Ahura Mazda to bring about the kingdom of righteousness in the material world (Nigosian 1993: 77). This section of the piece begins with musical material from the previous three sections, and eventually refers to all six previous sections. As the six sections return, I gradually superimpose them onto one another. In m. 180, m. 182, and m. 184, there are trills in the piano, flute, and clarinet parts, respectively. They are reminiscent of the Haurvatat and Vohu Manah sections. The same measures refer to the Spenta Armaiti section in the horn and trumpet parts. Metallic percussion instruments are used to reference the Khshathra Vairya section, especially in mm. 179-185. In mm. 171-203, the string parts are a fragmented version of the tremolo material from Haurvatat. In m. 176, the electric bass player strikes percussive notes that relate to the low rumbling sounds of the opening section, Ahura Mazda. All of these references combine in this section, briefly painting a sonic picture that brings together the various elements of the composition. As the Asha Vahishta section progresses, however, it increases in textural density through frequent superimposition. The overall sound becomes more chaotic. In approximately $\mathrm{m}$. 187, the chaotic material overwhelms the music, which now embodies the wicked and chaotic lord of $d r u j$, Angra Mainyu.

Angra Mainyu inspires the last section of the piece. In mm. 188-195, the string parts each transition from music that I notated strictly, to music that is senza misura 
(without meter). In the senza misura measures, pitch and relative positioning of the notes are clearly defined (see Notation for a more a detailed description). Each part's rhythm, however, is indeterminate. In m. 197, for example, the cello player must play five notes; an individual $\mathrm{B}^{\mathrm{b}}$ followed by an individual B natural, followed by three notes in one bow movement. The only other restriction is that the player must fit all five notes within the single measure. Each player spontaneously realizes a specific rhythm within each measure, which adds an element of chance or chaos to each performance so that no two performances are exactly the same. I utilize senza misura at three previous instances in the piece, mm. 141-145 in the string parts, mm. 100-102 in the right percussion part, and mm. 13-16 in both percussion parts. Reaching its apex in mm. 200-203, the chaotic material culminates in a triple forte chord on beat one of m. 204 . The chord contains nine separate tones in the outer ranges of each instrument and sounds intensely dissonant. Deep, quiet, and rumbling sounds in the electric bass immediately succeed the loud tutti cluster. This is a direct connection with the first moments of the piece, with some slight variations. The contrabass and cello support the electric bass with a low perfect fourth — when accounting for the octave transposition of the contrabass - of A quartertone sharp and D quartertone sharp, respectively. I emphasize only two microtone pitches in this piece: the two pitches that make up the particular perfect fourth mentioned above.

The opening section of the piece, Ahura Mazda, relates to the ensuing sections in that it contains fragments or elements of material to come. In several cases, the opening section includes a gesture or technique that serves as the basis of a succeeding 
section. This is intended to parallel the relationship between the Supreme Being, Ahura Mazda, and His six creations, the Spenta Armaiti. In the first measure, both percussionists perform finger rolls on the flexatones. Through the flexatone material, I foreshadow the Khshathra Vairya section's metallic theme. In m. 8 the electric bassist provides rhythmic material from which much of the piece is derived (see V-c. Rhythmic Motives for a more detailed description of the rhythmic material). Within m. 10, the music hints at the Spenta Armaiti section by introducing the antiphonal pair of trumpets. In m. 20, the flutist foreshadows later material with two simple two-note phrases. As a whole, one can perceive the opening section as a loose foundation for the following material. I use the term "overture" loosely in Figure 1. 


\section{ORCHESTRATION TECHNIQUES}

Druj Aeterni is the my largest instrumental chamber work. It requires one flute, one $\mathrm{B}^{\mathrm{b}}$ clarinet, one $\mathrm{F}$ horn, two $\mathrm{B}^{\mathrm{b}}$ trumpets, one piano, two percussion sets, a string quintet (two violins, one viola, one cello, and one contrabass), and one electric bass. The sum of players in the ensemble is fourteen and one conductor. There are a few unique requirements in the staging and instrumentation of the ensemble.

First, the ensemble is divided into three groups. The main group consists of the woodwinds, the horn, the piano, the string quintet, and the electric bass. Performers in this group sit centrally, i.e., middle stage. Each of the two percussion sets includes one trumpet player, forming two groups. The two groups split into a left group that stands stage left, and a right group that stands stage right. Overall, the ensemble's arrangement consists of two antiphonal trumpet/percussion duos flanking the central main group.

\section{IV-a. Percussion Specifications}

Each set includes one cowbell, one triangle, one pair of claves, two timpani, two cymbals, two toms, and a one octave set of crotales. The left percussion set includes one bass drum and one "tenor flexatone," while the right percussion set includes one regularly sized flexatone with the mallets removed, and one "bass flexatone." Instruments of the left percussion set are generally higher in relative pitch than the right percussion instruments. The left set's crotales range from three octaves above 
middle $\mathrm{C}$ to four octaves above middle $\mathrm{C}$, while the right set's crotales range from two octaves above middle $\mathrm{C}$ to three octaves above middle $\mathrm{C}$. In the left set, the triangle, cowbell, and clave should be smaller than their right set counterparts (equally sized is acceptable if differentiation is not possible). The two cymbals in the left set should be small (14" - 16") and medium (16" - 18"), while the two cymbals in the right set should be medium (16" $\left.-18^{\prime \prime}\right)$ and large (18" $\left.-24 "\right)$. It is acceptable for the medium cymbals to be of equal size; otherwise the left set must contain the smaller of the two. In contrast to the general trend, the toms of the right set should be small and medium, while the left set contains small, medium, and large toms. Similarly, the timpani should be 32 " and $29 "$ or 28 " for the left set, and 30 " and 26 " or 25 " for the right.

It is important to note that the percussionists do not always play the cymbals and crotales in a conventional manner. Often times, the percussionist is required to scrape the surface of the cymbal with a metallic object. Since the technique frequently occurs in quick succession with other conventional techniques, the percussionist should attach a small key or metal dowel to the end of one handle in each pair of mallets. This allows the percussionist to perform the scrapes without changing mallets. One can find " $\mathrm{x}$ " note-heads representing cymbal scrapes in $\mathrm{m} .26$ and m. 67 of the left percussion part (see V-a. Notation for further description).

In other instances, I compose for bowed crotales and bowed cymbals. There are examples of bowed crotales in mm. 64-66 of both percussion parts. In m. 99 and m. 121 , the left percussionist uses a bow on the cymbals. In both instruments, the duration of the notes corresponds to the duration of bowing. 
IV-b. The Flexatones

I first heard the flexatone in a piece by Jacob Druckman, titled Aureole. Druckman includes two flexatones in the piece (Druckman 1979), and one can hear its sound five measures before $10 \mathrm{~A}$ and six measures after $10 \mathrm{~A}$. The flexatone is a strange yet simple modern percussion instrument with a very unique sound. Commercially, the flexatone can be purchased in two sizes, regular and small. Flexatones consist of a thick oblong wire frame fastened to a small bent sheet of steel. The manufacturer attaches two small mallets with hard woodenheads to both surfaces of the steel sheet. Percussionists can easily hold and play the instrument with one hand by shaking the instrument back and forth while using their thumb to further bend the sheet of steel. Bending the sheet of steel creates greater tension, thus producing higher pitch. As is, the wooden mallets limit the variety of playing techniques since every attack is sharp and repetitive. I have chosen to remove the mallets, allowing the percussionists to strike the steel surface with their free hand. This modification provides much greater control over the rhythm and the variety of sounds.

Since the basic idea of the instrument - a large sheet of flexible metal - is very simple, I decided to build much larger versions. The "tenor flexatone" is a 1' x 2' flexible sheet of zinc-plated metal, available at most home improvement stores. Likewise, the "bass flexatone" is a 2' x 3' sheet of zinc-plated metal. Initially, I expected that the larger sizes would limit the diversity of playing techniques, however, the opposite is true; the sizes create greater resonance and more versatility. One disadvantage of the larger flexatones is that they require two hands for most playing techniques. Usually, the 
percussionists must use one hand to hold one edge of the flexatone and place the opposite edge on a suitable holster. A conventional music stand with one central column and three legs may serve as a holster if the stand lies horizontally on the ground with one leg pointing vertically upwards. The opposite edge of the flexatone may rest in the right angle formed between the vertical leg and the central column of the music stand. The player can secure the apparatus by placing one foot on top of music stand near the area where sheet music normally rests. This arrangement leaves percussionists with one free hand, which they may use to achieve three basic playing techniques.

Two of the playing techniques are conventional attacks with various mallets. I call the first, "flat strikes," and the second, "edge strikes." Measures 104-105 of the percussion right part provide examples of flat strikes. This attack, as the name implies, requires striking the surface or flat side of the flexatone. In mm. 108-110 of the same part, I incorporate the second playing technique, edge strikes. Edge strikes require striking the flexatone anywhere along its thin edges, preferably attacking with the handle of the mallet. The result decays more quickly, and produces different harmonic partials than the flat strikes. Both techniques are conventional mallet strikes, therefore I notate them with normal note-heads (see V-a. Notation). The third playing technique is scraping, which I refer to as "circular scrape," in m. 57. This technique is most effectively achieved with metal brushes, but may be performed with any metallic object.

Additionally, there are three unconventional playing techniques for the tenor and bass flextones. I name the first technique "finger roll." Finger rolls appear in the percussion parts during the very first measure of the piece, and in $\mathrm{mm} .29,106$, and 
207. Instead of a mallet, the percussionists rapidly bounce the index and middle fingers of their free hand against the corner of the flexatone's flat surface. The motion is similar to playing very fast repeated notes on an electric bass with the right hand.

Alternatively, percussionists can vigorously shake their free hand in the same vicinity, allowing the thumb and little finger to rapidly bounce on the instrument's surface. The latter approach is more apt for louder dynamic markings. The sonic result of this technique is an eerie metallic rumbling noise with varied pitch.

I call the second unconventional playing technique "two-handed shake." This technique is especially effective on the bass flexatone, which is more flexible and resonates more loudly. To accurately perform this technique, the percussionist must lift the flexatone, with both hands, above its holster. The percussionist should hold the top two corners of the instrument, allowing the 3 ' long side to dangle from about the chest to the knees. They should then shake each hand to and fro, alternatively. As the alternating shaking becomes more rapid, the dynamics become louder. What is produced sounds similar to a thunder sheet, but not quite as low and heavy. Twohanded shakes resemble sonically a mixture of the finger roll and the final playing technique, which I call the "pwop."

"Pwop" onomatopoeically represents the sonic result of the corresponding playing technique. This technique requires the percussionist to use two hands to hold opposite edges of the flexatone, lengthwise. By allowing the flexatone to rest completely tension-free, then suddenly adding tension so that the ends bend closer together, the player can create a short pop of punchy metallic timbre. Measure 114 includes a tenor flexatone pwop in the left percussion part, and m. 86 contains a bass 
flexatone pwop in the right percussion part. The tenor flexatone is more maneuverable and so creating a pwop is easier on this instrument.

\author{
IV-c. The Electric Bass
}

The only amplified instrument in Druj Aeterni is the electric bass. As such, I choose to use the instrument as a sort of atmospheric support to the other instruments and material. In most instances throughout the piece, the electric bass player uses unconventional styles of playing, in conjunction with an unusual scordatura (mistuning) and various digital effects. The only string left in its original tuning is the G string, allowing the bass to retain a hint of its normal timbre. String IV — usually the E string — should sound almost a perfect fifth lower, down to an A quartertone sharp. The bassist must lower string III — normally the A string — by one quartertone, to A quartertone flat. Lastly, the bassist must raise string II — normally the D string — by one quartertone, to D quartertone sharp. Detuning string IV extends the lower range of the electric bass, and augments the ominous rumbling quality in places like m. 1, m. 125, and m. 197. String III adds novel color to the pitch possibilities of the bass, while string II completes a reoccurring interval that permeates the piece - the perfect fourth between A quartertone sharp and D quartertone sharp.

To further the novel timbre of the electric bass, I require unconventional playing techniques and some basic digital signal processing. One of the playing techniques involves a hard plastic object, such as lighter or plastic slide (metal or glass is also acceptable). Using the right hand — assuming the bass player is right-handed — the 
bassist maintains continuous contact between the slide and the desired string. The contact point produces pitch if the player begins applying a steady vibrato to the right hand. One can find examples of this in mm. 49-67 and m. 114 of the electric bass part (see V-a. Notation for further explanation).

A second playing technique requires the bassist to use the slide percussively, quickly bouncing it off of the bridge or desired string. Measures 109 and 120 show examples of this technique. Each " $\mathrm{x}$ " note-head represents one percussive bounce. Bouncing the slide becomes more percussive as the point of contact approaches the bridge, but is almost like a contrabass pizzicato as the point of contact departs further from the bridge and approaches the fretboard. I exploit this sonic link and surround the electric bass material with contrabass - a pizzicato G in m. 108, and col legno battuto gestures in $\mathrm{m} .110$ and $\mathrm{m} .112$.

The third and final playing technique is really a simple modification of how one would normally play the electric bass. The bassist must reduce the volume knob to completely muted, play the specified note, and quickly return the volume to the appropriate level. I call for this technique so that the pitch and resonance of the notes sound, but the attack does not. Since the digital signal processing includes delay, this third playing technique disguises the attack well but still allows the pitch and resonance to undergo the digital processes. I employ this technique frequently, such as in $\mathrm{mm}$. 8590, m. 93, m. 113, m. 157, and several other measures (see V-a. Notation for examples). Digital signal processes affecting the bass include delay, reverb, and pitch shifting. There are different ways for the bassist to realize the processing, including the Digitech BP200 or comparable bass pedal, or using the program Max/MSP. There are 
two separate effect processes that I specify in Druj Aeterni. The first I call, "Effect 1," and the second I call, "Effect 2." Effect 1 implements a continuous delay of 1.9 seconds with a feedback level of 61 hundredths (61\%). The signal also receives a so-called "church" reverb with a decay of 81 hundredths (81\%), at an amplitude level of 80 hundredths (80\%). There is no pitch shifting in Effect 1. Effect 2, however, implements a proportional major third shift up from the input pitch. Thus, the output pitch is a major third higher than what I notate in the electric bass part. Effect 2 also includes a delay of 1.3 seconds with a feedback of 73 hundredths (73\%), and a so-called "room" reverb with a decay of 59 hundredths (59\%) at an amplitude level of 35 hundredths (35\%).

In Effect 1, the heavy saturation of delay and reverb intensifies the low rumbling qualities of the detuned electric bass. Delay also provides for interesting rhythms and resonance that echo beyond the point at which the bassist stops playing. In $\mathrm{m} .17$, for example, the bassist gradually fades the volume knob to zero, but the resonance continues to sound into m. 18 and even m. 19. In contrast to the rumbling saturation of Effect 1, the delay and reverb of Effect 2 behave more like resonance extenders. Pitch shifting in Effect 2 changes the timbre of the output in addition to the pitch. Some of the resulting pitches appear nowhere else in the piece. For example, the bassist plays an A quartertone sharp in $\mathrm{m} .124$ and a D quartertone sharp in $\mathrm{m} .125$, which results in a C three quartertones sharp and an F three quartertones sharp, respectively.

The bassist, in addition to implementing various digital effects, must also make use of a loop pedal or looping program. I require the storage of two separate bass loops. Included in the bass part are specific instructions on when to begin recording, 
when to stop recording, and when to playback recordings. The first loop, Loop A, must be realized through a device capable of standard looping playback only. Loop B, the second loop, must be realized through a device capable of reverse playback the instant at which the loop finishes recording. Each loop must be able to indefinitely and independently repeat. Loop recordings must include the other digital processes.

\section{IV-d. Other Instruments}

Within the central ensemble, I require remarkable playing techniques of the piano. Frequently, the piano player must reach inside of the piano and pluck certain strings with their fingernail, e.g. in mm. 60 and 76 of the piano part. Similar to the cymbal scrapes, the pianist also scrapes their fingernail across certain piano strings with the damper pedal depressed, e.g. in m. 26 and m. 61. Both the cymbal scrape and the piano fingernail — or "f.n." — scrape bear a similar "x" note-head (see V-a. Notation for examples of the " $x$ " note-head). 


\section{BASIC TECHNIQUES}

This section of the paper discusses my notational techniques, the pitch materials, the rhythmic motives, and vertical and horizontal models of the compositional elements. Before discussing the compositional elements, it is necessary to have a complete understanding of the notation of Druj Aeterni. Most of the piece contains standard 5-line musical notation, with time signatures, rhythm, and specified pitch. There are several instances, however, where the style of music requires different or unconventional notational techniques - mostly in the percussion and electric bass parts.

\section{V-a. Notation}

Normally, one notates the electric bass with a single 5-line staff in bass clef. Throughout the score, however, the electric bass part contains two staves - one normal staff on top, and a one-line staff on the bottom. The bottom staff instructs the player in volume knob settings. In visual resemblance to the physical volume knob, the clef of the bottom staff is a large "X" circumscribed by a circle. Example 7 shows the clef of the bottom staff. The small "0" indicates that the volume knob should equal zero, i.e., no volume. Standard musical dynamic markings indicate a relative sense of volume knob positioning when it is not equal to zero. The bottom staff supplies a convenient way of notating the third playing technique discussed above (see IV-c. The Electric Bass). Example 7 from mm. 152-154 displays the way in which the notation supports 
the playing technique. Notice how the quarter note lines up directly above the zero volume marking, showing the bassist that the initial attack does not sound.

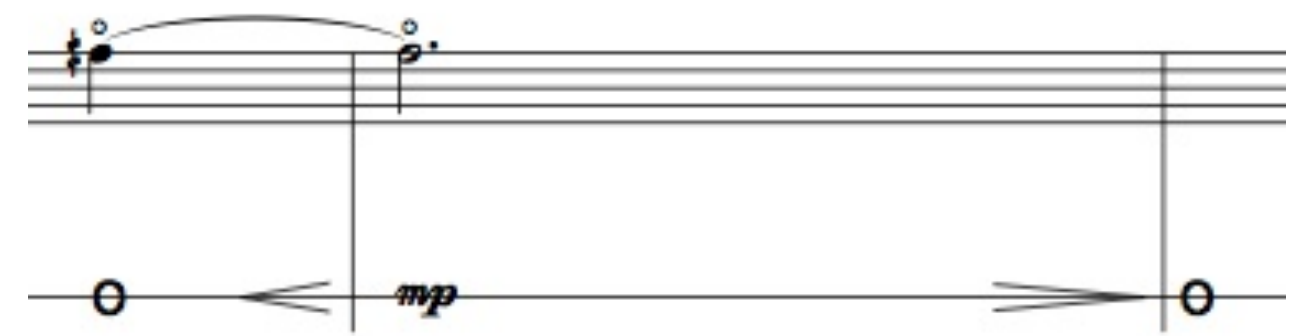

Example 7 - The top staff specifies the pitch and rhythm for the bassist. The bottom staff shows how the volume knob control synchronizes with the rhythm.

Example 7 above includes a standard 5-line staff for the top staff. In some instances, however, I switch to a 3-line staff that no longer denotes specific pitch.

Example 8 and Example 9 show the 3-line staff and its accompanying rectangular clef. The clef represents the relative point at which the slide contacts the string.

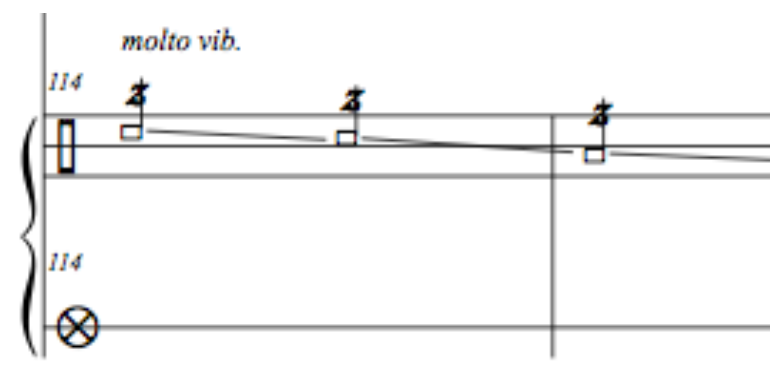

Example 8 - In this excerpt, the contact point between slide and string is initially near the bridge, but slowly descends towards the last fret. A contact point nearer to the bridge produces a pitch that is higher relative to a contact point further from the bridge. 
The top line of the three represents a point of contact that is one millimeter away from the absolute end of the string, very near the bridge. If the note-head is close to the top of the three lines, then the bassist should make contact close to the bridge, e.g., the leftmost note of Example 8 or every note in Example 9. The bottom of the three lines represents a point of contact at precisely the last fret of the fretboard. This point does vary from bass to bass; nonetheless it is a good reference point. Any note that lies between the outer two lines represents a relative positioning between the bridge and the last fret of the fretboard. Example 8 includes rectangular note-heads, which serve to notify the bassist that he or she should maintain continuous contact between the slide and string. In general, rectangular note-heads denote playing techniques that involve rapidly recurring movement or techniques that do not utilize a mallet. The constant right-hand vibrato with the slide is the recurring movement required here.

In contrast to the note-heads of Example 8, Example 9 includes "x" note-heads. These signify a short percussive bounce of the slide against the string.

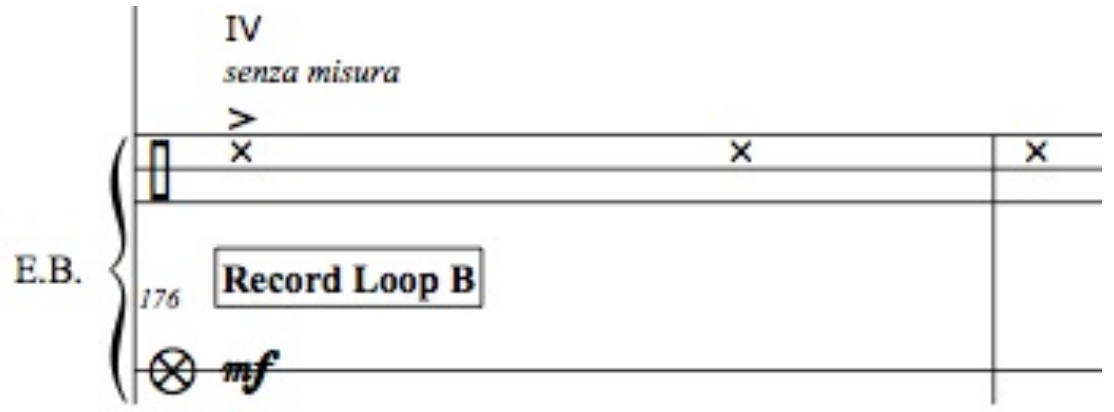

Example 9 - In this excerpt, the bassist plays three percussive bounces on the same string and at the same point of contact between slide and string.

In Example 9 I retain the 3-line staff but apply it to a different playing style. 
Example 9 from m. 176 contains three other items of notational significance. The first item is quite conventional: the Roman numeral "IV." It denotes the desired string, as usual in modern fretted instrument notation. Secondly is the rectangular box containing the words "Record Loop B." This is an example of the looping instructions that I include in the electric bass part. Measure 196 contains the playback instructions for Loop B, “Reverse Playback Loop B." This means that during measure 196, the bassist must finish recording Loop B and immediately playback the recording in reverse. Thirdly is the phrase "senza misura." As discussed previously in the Asha Vahishta section, this technique adds to the chaotic nature of the piece. Example 9 shows a measure in which the bassist must realize two separate percussive attacks in one measure of $2 / 4$. Since the second note is slightly more than halfway through the measure, the player would know that he or she should strike sometime between the $2^{\text {nd }}$ beat of $\mathrm{m} .176$ and the first beat of $\mathrm{m} .177$. There are no stems on the note-heads within the senza misura measures to avoid implying rhythmic duration. Measures 141-145 incorporate the use of senza misura in every part of the string quintet.

In the two percussion parts, there are additional items that warrant notational clarification. Example 10 shows an excerpt of both percussion parts from mm. 106108. The first thing that one might notice is the similarity between the 3 -line notation here and the 3-line notation in the electric bass part. 


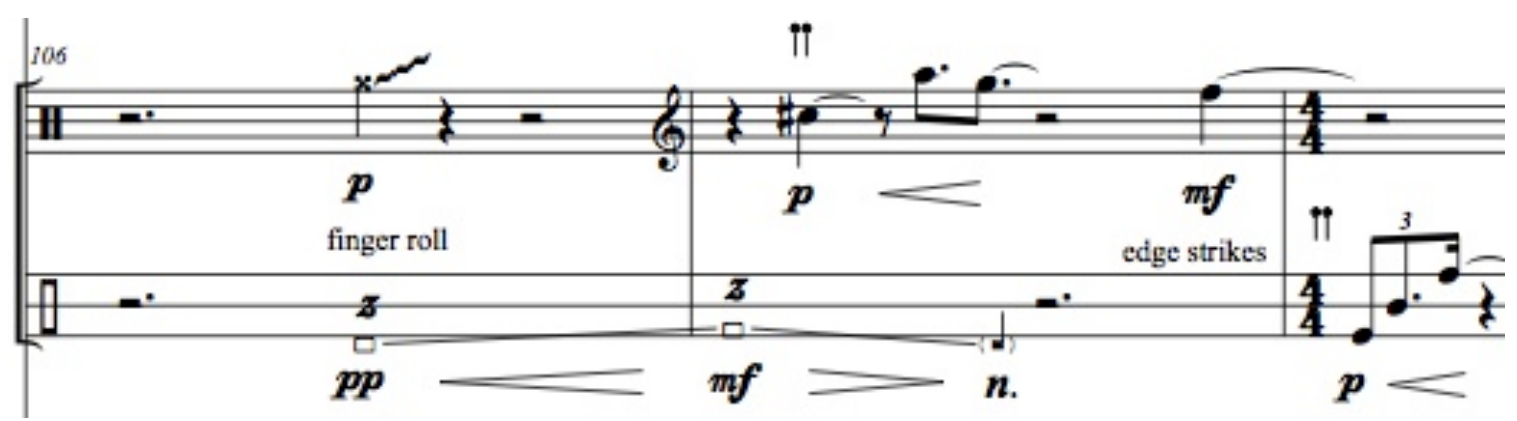

Example 10 - Similar to the 3-line staff in the electric bass part, the 3-line staff in the percussion parts indicate relative tension applied to the flexatones. Lower notes indicate less or no tension and higher notes indicate greater tension.

Notational similarity exists because the underlying concept of each playing technique is the same. In the percussion parts, the 3-line notation with a rectangular clef denotes the flexatone instruments. Notes in the space below the bottom line represent zero tension in the flexatone, while notes above the top line represent a high degree of tension. Just as the bassist must judge relative positioning of the notes and translate that to slide placement, so too must the percussionists judge relative positioning of the notes and translate that to the level of tension in the flexatone.

The "finger roll" is notated with rectangular note-heads. Here, the bouncing of the fingers against the surface of the flexatone is the rapidly recurring movement. Small rectangular notes in parenthesis serve as a tension target while the roll approaches niente (nothing). I compose with regular note-heads in $\mathrm{m} .108$, and in all other places where the percussionist must play the flexatone with regular mallet techniques. I chose to notate the flexatone "pwop" with rectangular note-heads because the technique does not utilize mallets. The "pwop," however, does not involve rapidly recurring movement. In $\mathrm{m} .107$, three of the notes in the crotales part are connected to ties. The ties connect to rests and instruct the percussionist to allow the notes to vibrate indefinitely. 
Since no rest separates the dotted eighth A-G figure, the notation implies that both the A and the $G$ should vibrate indefinitely. Only if a rest follows a note with no connecting tie should the percussionist mute a sounding tone. Scraping the cymbal is the only exception; this should always vibrate indefinitely. The piano part also contains notes tied to rests to denote indefinite sustain.

\section{V-b. Pitch Organization}

Druj Aeterni's pitch scheme revolves around ten chromatic pitches and two microtonal pitches. A perfect fourth interval separates the two microtonal pitches, A quartertone sharp and D quartertone sharp. The ten chromatic pitches are $\mathrm{C}^{\#}, \mathrm{D}, \mathrm{E}^{\mathrm{b}}, \mathrm{E}$, F, F\#, G, A, B $\mathrm{B}^{\mathrm{b}}$, and $\mathrm{B}$. Thus, $\mathrm{C}$ and $\mathrm{A}^{\mathrm{b}}$ are the two chromatic pitches not included. I omit these two pitches intentionally, attempting to vacate the vicinity of the two microtonal pitches, thus highlighting their occurrences. On a broad scale, Druj Aeterni is atonal. There are sonic microcosms, though, where I hint at certain tonalities. These microcosms of tonality represent the overall conceptual theme of the piece; pockets of order exist within a broader scale of chaos - chaos refers to atonality in this case. The possibility of tonality arises from two avenues; firstly by virtue of the pitch scheme's whole-step gaps left between B and C\#, and between G and A. Secondly, this possibility arises by my conscious focus on some subset of the pitch scheme.

I incorporate the pitch scheme vertically and horizontally. Vertically speaking, the pitch scheme guides the content of cluster chords and sonorities. The climax of the piece in m. 204, for example, contains a cluster chord of nine pitches, all within the pitch 
scheme. Horizontally speaking, the pitch scheme outlines the melodic content of the woodwinds, brass, and piano parts. The horn part precisely follows the pitch scheme in mm. 78-79, for example. For more details on pitch organization, see chapters VI and VII.

\section{V-c. Rhythmic Motives}

There are two sources of the music's rhythmic motives, my fascination with prime numbers and a two-note motive first introduced by the electric bass in m. $8-\mathrm{a}$ dotted eighth note followed by a sixteenth note. The two-note motive undergoes intense rhythmic variation including elongation and fragmentation. In m. 28, the original motive is elongated by a sixteenth note, appearing in the piano part as a minor $7^{\text {th }}$ descent from $E^{b}$ to $F$. Extremely elongated versions of the two-note motive arise in mm. 28-30 of the clarinet and flute parts. The clarinetist plays a retrograde version that includes an augmentation of the sixteenth note into an eighth note tied to a quarter note triplet. An augmented retrograde version appears in the flute part, but in this variation the sixteenth becomes a dotted eighth.

I use the two-note motive to layer each string entrance in $\mathrm{mm}$. 33-38. The contrabass and cello parts include retrograde elongations, and the viola part has an elongation that repeats and accelerates into a tremolo. This tremolo is the foundation for the dense tremolo cloud that distinguishes the Haurvatat section. After taking the two-note motive to one extreme, the string section mostly rests until m. 127. Here, the two-note motive is heard as two staggered pizzicato entrances in the viola and cello. The gradual process of staggered layering begins as it did in $\mathrm{m} .38$, but this time as 
pizzicato and col legno battuto playing techniques. By m. 136, the entire string section plays rapid and percussive pizzicato notes. Once again, the two-note motive becomes the foundation of a much denser rhythmic cloud that defines an entire section, Vohu Manah.

In the percussion parts, one can find many instances where the two-note motive returns or is varied. I slightly augment the two-note motive to create a sort of dialogue between timpani in mm. $45,47,53$, and 61 . The left percussionist plays the medium tom-tom, recalling the two-note motive in its original form in $\mathrm{m}$. 39. Two measures later, the lower tom-tom echoes in retrograde form. In mm. 87-89, the left and right percussionists superimpose several iterations of the two-note motive using the claves. On beat four of $\mathrm{m} .118$, the left percussionist plays an elongation of the two-note motive using the cymbals, and the right percussionist plays a diminution of the two-note motive on the bass flexatone. The left percussionist plays a diminution of the two-note motive with the cowbell in the second beat of $\mathrm{m}$. 140. These are but a few of the numerous examples where the percussionists play variations of the original two-note motive.

My fascination with prime numbers can be found in several of my compositions, but in Druj Aeterni it plays a crucial structural and conceptual role. The two-note motive is itself based off of a prime number. It can be very limiting, however, to use only one prime number. Of the prime numbers, three, five, and seven structure the rhythms of all individual motives, and structure the overall phrase groupings that encompass the individual motives. Example 11 shows the phrase groupings of the claves in mm. 87-89. 


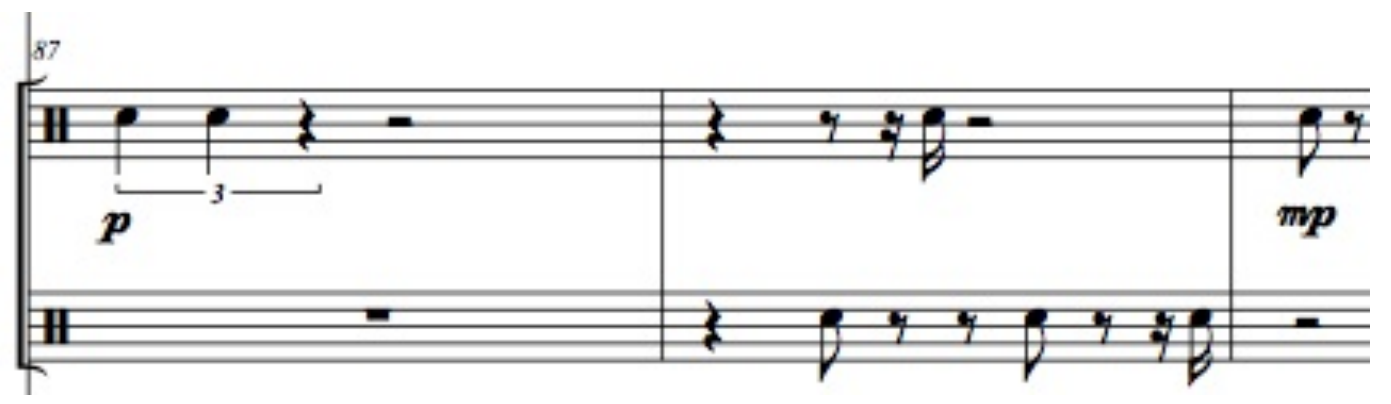

Example 11 - This excerpt shows rhythmic phrases involving a prime number of notes. The top staff is the left percussion part, and the bottom is the right.

Notice how the left percussionist (top staff) enters with a group of two notes - a prime number. Then he or she plays two single note entrances. The right percussionist, in m. 88, plays a group of three notes - also a prime number. In this phrase, the total number of clave notes is seven - a prime number.

The clarinet and flute parts include the frequent use of prime numbers during fast melodic runs. Example 12 includes four entrances that clearly illustrate my frequent use of prime numbers.

$\mathrm{B} b \mathrm{Cl}$.

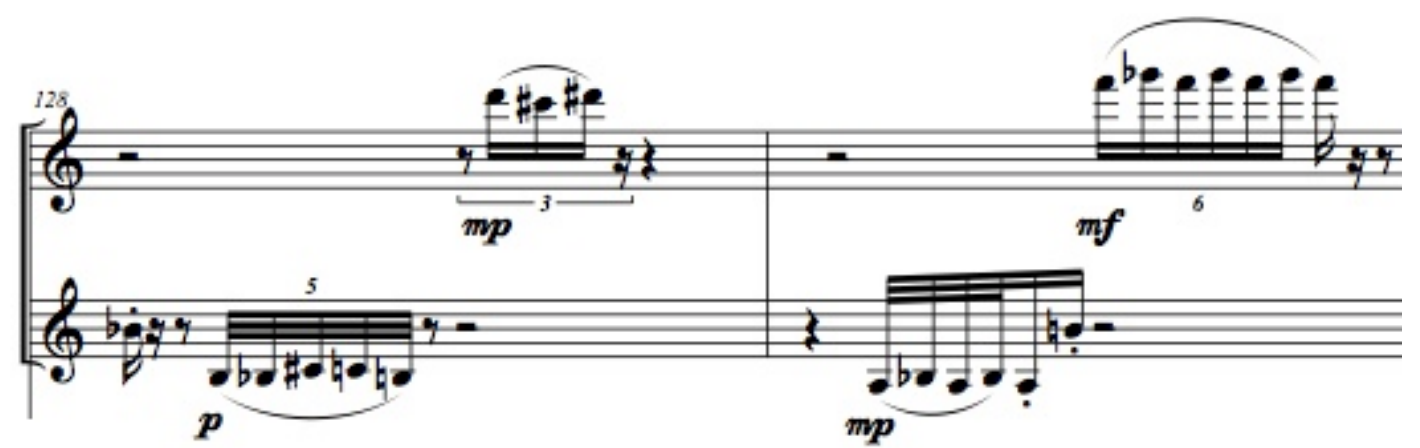

Example 12 - This excerpt shows passages that contain prime number groupings of slurred notes.

In $\mathrm{m} .128$, the clarinetist plays a five-note figure, followed by the flutist's three-note figure. In m. 129, a form of rhythmic elision combines the clarinetist's five-note figure 
with a two-note staccato rhythm, which then leads to a seven-note figure in the flute part.

Example 13 shows a dense layering of arco strings from m. 201. The clef and pitch of the excerpt are not included since the example pertains only to rhythmic phrasing. I group each arco phrase into a prime number of component notes. In the violin I part, the top staff contains bow phrases of three, two, and 5 notes. The violin II part contains bow phrases of two and three notes, the violist plays phrases of two, three, and five notes, and the cellist plays phrases of two notes. I compose individual accented notes for the cello more frequently than the higher strings because the cello is meant to sound more percussive.

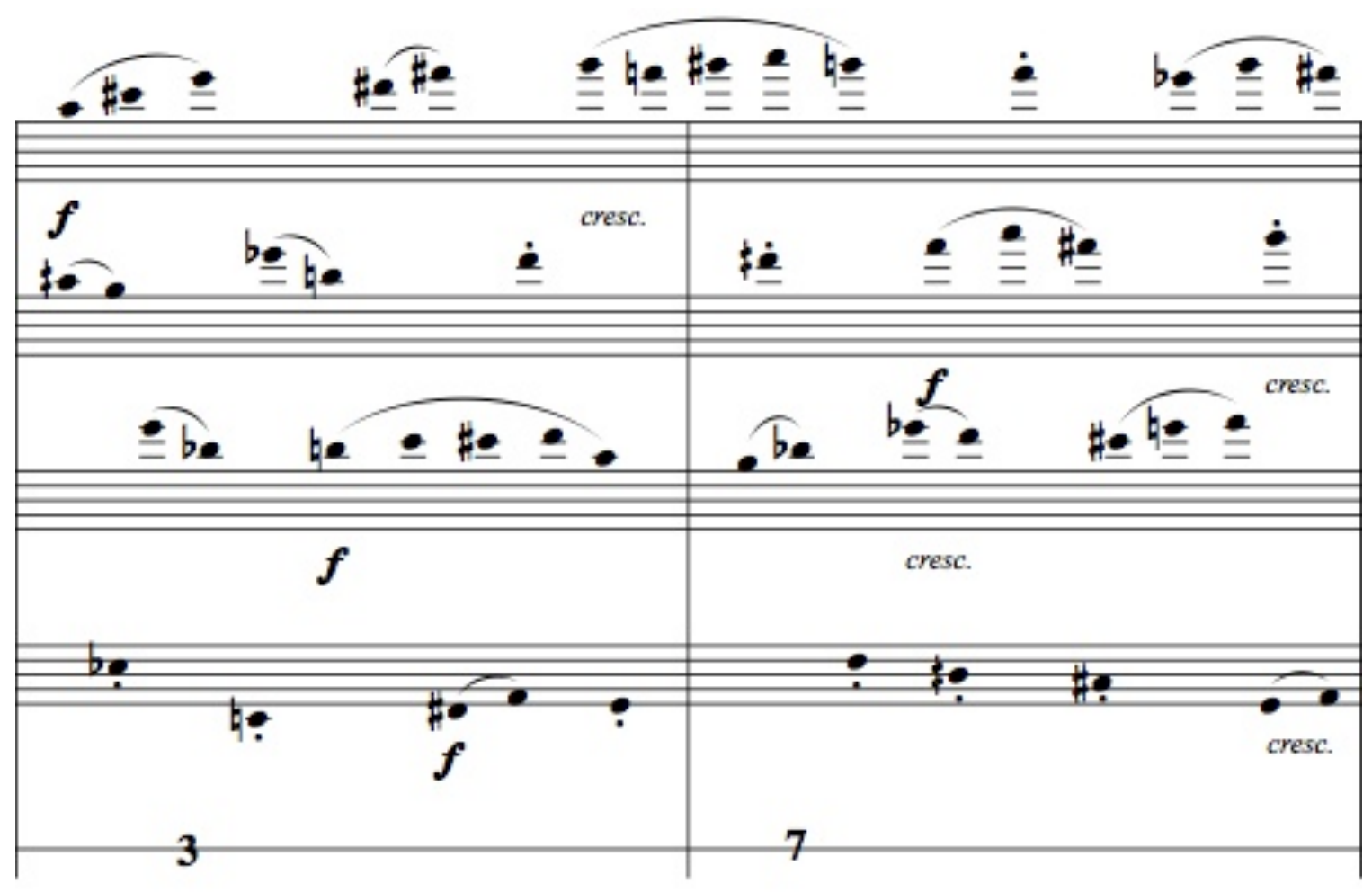

Example 13 - This excerpt shows mm. 201-202 of the string section. Similar to the previous example, I tie the notes into prime number groupings. 
The contrabass player must attack the strings col legno battuto while muting the strings with the left hand, and imitate the rhythms generated by the delay of the electric bass. Numerals on the single horizontal line in Example 13 indicate the sum of strikes performed by the contrabass player. 


\section{VERTICAL MODELS}

This section provides three examples of the how the pitch scheme relates to cluster chords in Druj Aeterni. Vertical models abide by the pitch scheme (C\#, D, Eb, E, F, $F^{\#}, \mathrm{G}, \mathrm{A}, \mathrm{B}^{\mathrm{b}}, \mathrm{B}, \mathrm{D}$ quartertone sharp, and A quartertone sharp). Example 14 shows a particularly important cluster in $\mathrm{m}$. 65 of the brass section and flute. The left trumpeter plays an $\mathrm{E}$, the right trumpeter plays an $\mathrm{E}^{\mathrm{b}}$, and the flutist plays an $\mathrm{F}$, building a threenote cluster that is outlined by one whole-step. This three-note cluster returns in several variations.

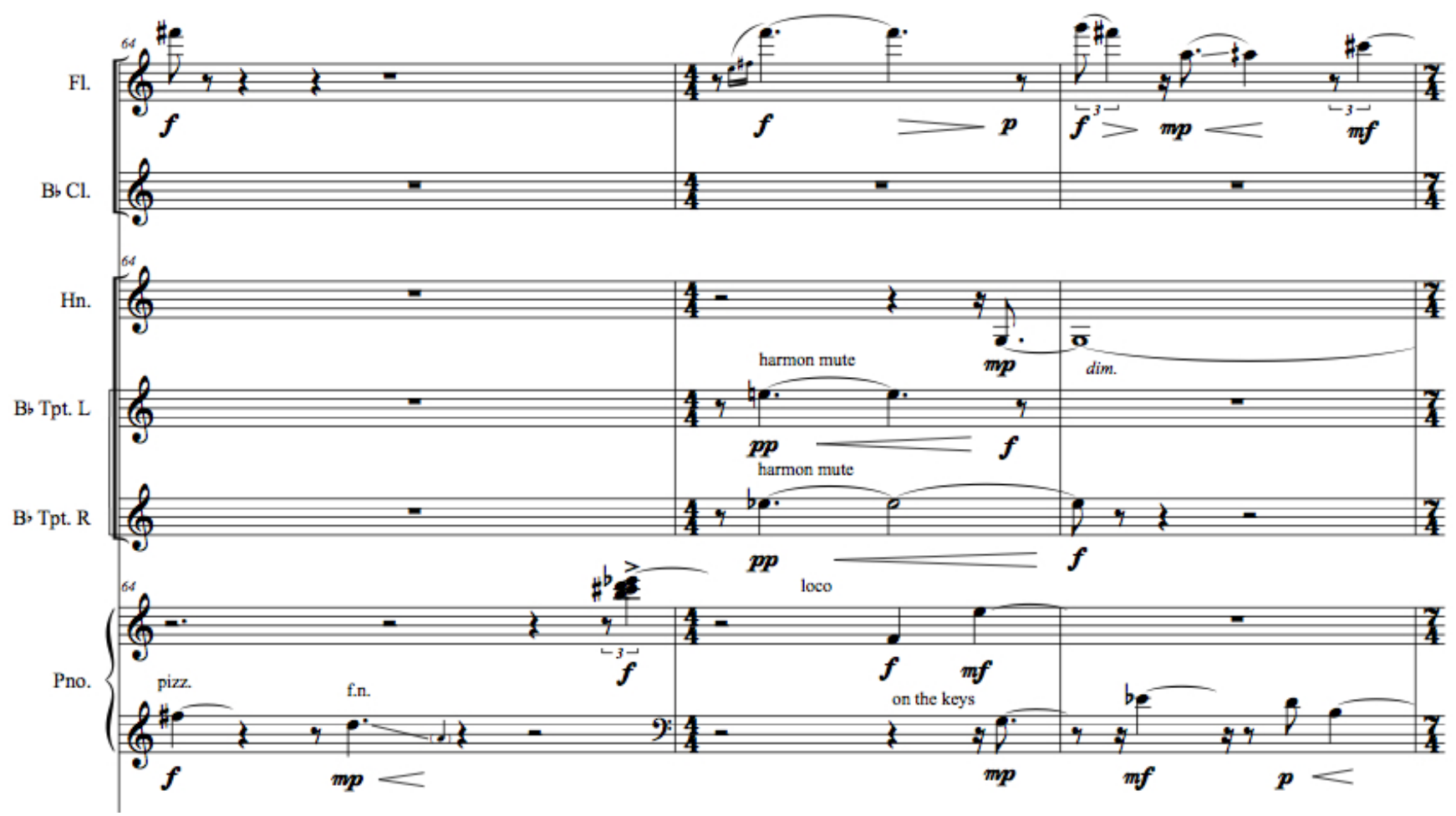

Example 14 - In measure 65, I use the trumpets and flute to introduce an important three-note cluster.

I present the three-note cluster as a linear piano passage in Example 15. 


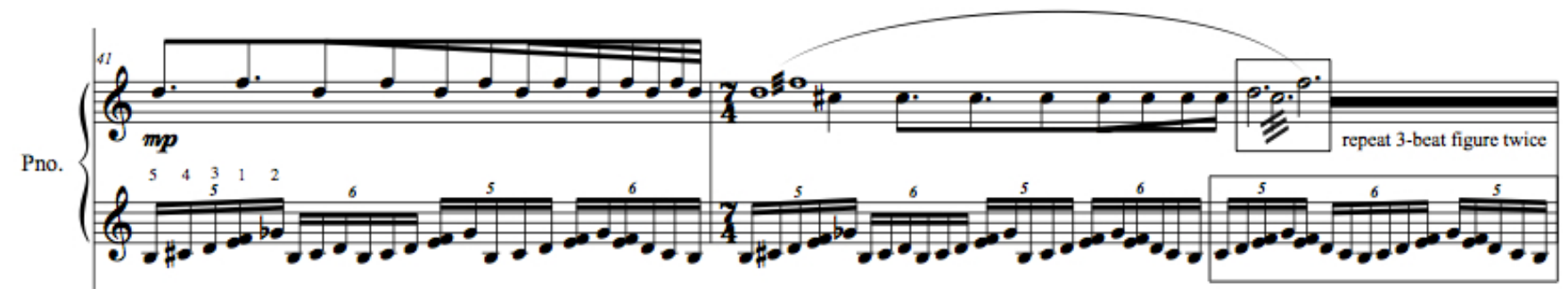

Example 15 - In m. 42, the pianist rapidly repeats D, F, and $C^{\#}$, producing a vertical three-note cluster.

In the second measure of the excerpt, the pianist plays a tremolo between $\mathrm{D}$ and $\mathrm{F}$, while rhythmically accelerating a $\mathrm{C}^{\#}$ ostinato. The three-notes eventually combine into one all-encompassing irregular tremolo on beat five. Here, tremolo technique creates a vertical cluster of continuous attacks.

The pitch scheme is the basis for the layering of tremolo strings in the Haurvatat section. Example 16 displays the pitch content of the tremolo strings in $\mathrm{m}$. 51 . In the viola part, the $\mathrm{C}$ is actually a $\mathrm{C \#}$, which was sustained from a previous measure.

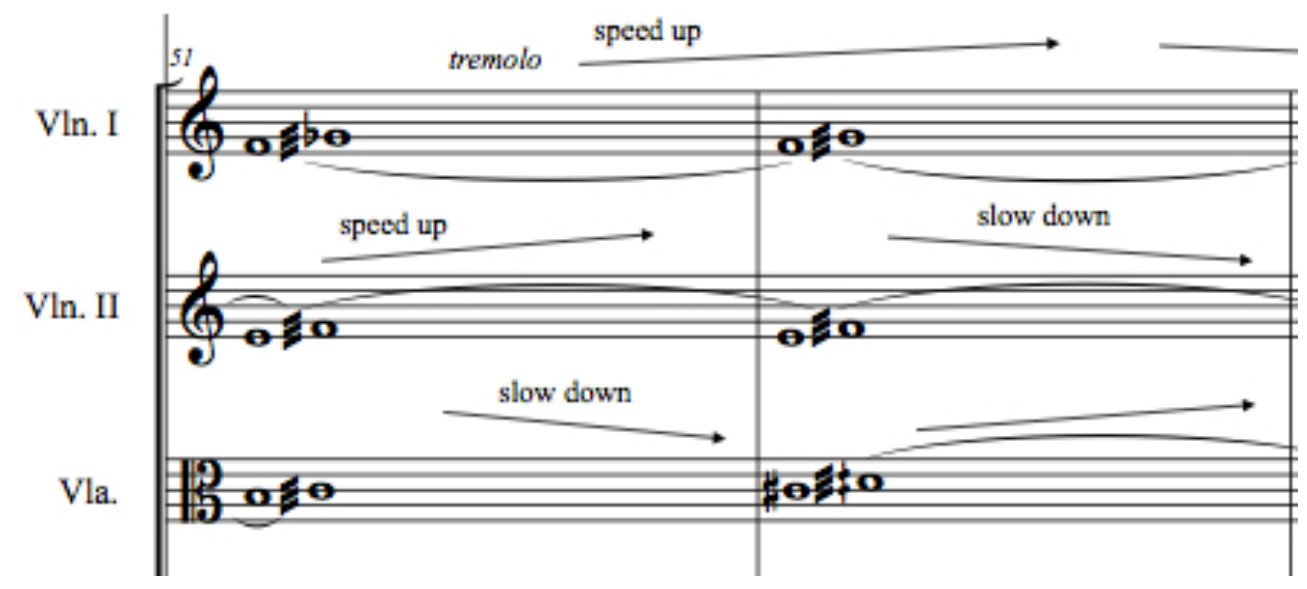

Example 16 - This excerpt shows part of the densely layered tremolo string technique from the Haurvatat section. The pitch content of each individual tremolo abides by the pitch scheme. 
Every note in Example $16-F, G^{b}, E, B, C^{\#}$, and D quartertone sharp - comes from the pitch scheme. 


\section{HORIZONTAL MODELS}

Provided here are three examples of the melodic content within Druj Aeterni and how it upholds the pitch scheme of the piece. I reconstruct the melodic content from previous sections to formulate later sections. Example 17 includes a figure in the right trumpet part, measure 70, which serves as a foundation for the brass-featuring section Spenta Armaiti.

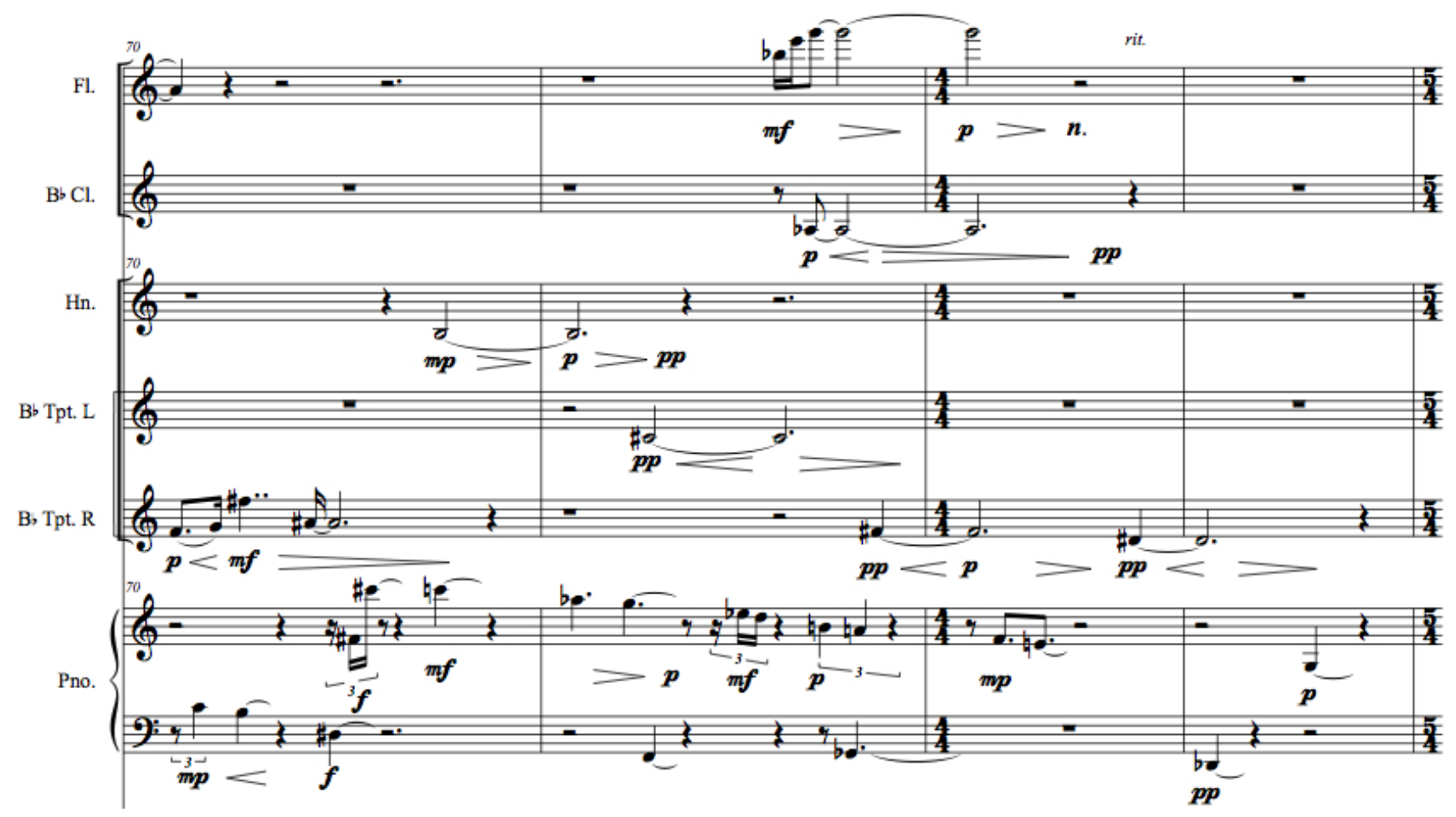

Example 17 - This excerpt shows a trumpet gesture in $\mathrm{m}$. 70. The gesture becomes the foundational material for the Spenta Armaiti section.

The right trumpet part also incorporates the original two-note rhythmic motive discussed in the Rhythmic Motives section. Thus, the Spenta Armaiti section is really a distant variation of the same motives that are found in the first two sections. On beat 
five of $m .71$, the pitches $B^{b}-E-G$ are heard in the flute part, foreshadowing the Spenta Armaiti section. Starting in $\mathrm{m} .71$ of the piano part, one can find ten of the twelve pitches that make up the pitch scheme. The pitches are $A^{b}, G, F, E^{b}, D, B, G^{b}, A, F, E, D^{b}$, and $\mathrm{G}$ are heard in succession. This brief passage includes all ten of the ten distinct chromatic tones that make up the pitch scheme.

Example 18 displays the Spenta Armaiti section's opening notes in the trumpet part, $\mathrm{mm} .74-76$. Notice the similarities between the arpeggio in $\mathrm{m} .75$ and the flute arpeggio in $\mathrm{m}$. 71 . Instead of climbing to a $\mathrm{G}$, the trumpeter plays $\mathrm{Bb}-\mathrm{E}-\mathrm{C}$, and then descends to a final $\mathrm{G}^{\#}$. I deliberately avoid the pitch scheme here, in order to announce the start of this significant passage.

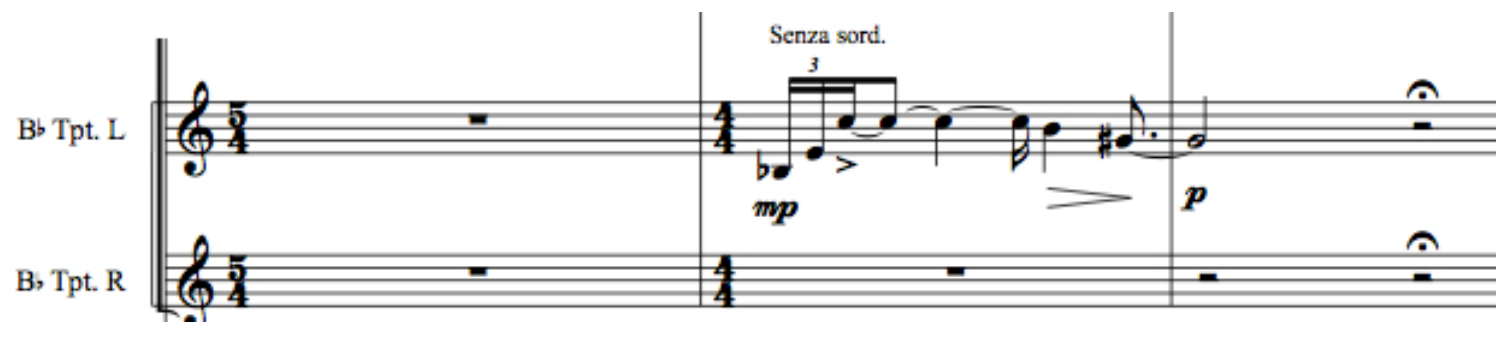

Example 18 - In this excerpt, the gesture from $\mathrm{m} .70$ returns in a varied form.

The last example, Example 19, includes trills, piano string plucking, and melodic horizontal use of vertical piano clusters. In m. 132, I compose four piano clusters in quick succession. Each individual cluster contains tones from the pitch scheme, but the pitches from the clusters are combined to create a kind of pointillist melodic motif. The distance between the first two clusters is almost three octaves, while the distance 
between the third and fourth is two octaves. In prelude to the coming pointillist clusters, the pianist also plucks the $A$ and $\mathrm{B}^{\mathrm{b}}$ strings on beat four of $\mathrm{m} .131$. The clarinetist elongates the plucked $\mathrm{A}$ and $\mathrm{B}^{\mathrm{b}}$ via a trill figure beginning on beat four of $\mathrm{m}$. 131. As is with the vertical models, most of the horizontal material strictly follows the pitch scheme.

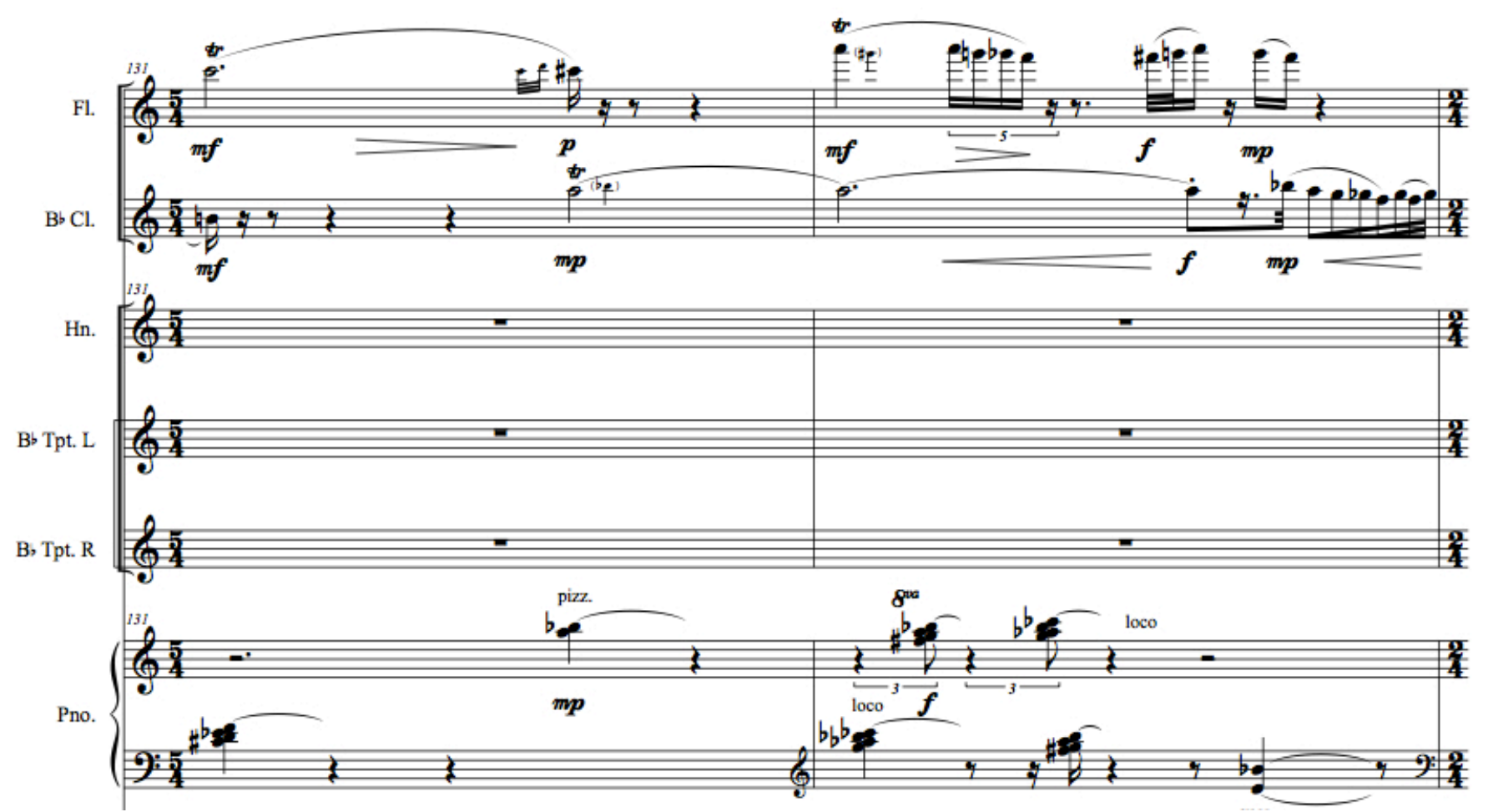

Example 19 - This excerpt shows Example 6 in context with some of the other instruments. Both the piano clusters and woodwind trills adhere to the pitch scheme of the piece. 


\section{STYLE}

Giacinto Scelsi's piece, Uaxuctum, played a large role in shaping the conceptual content of my compositions. While Druj Aeterni is not a programmatic piece, it does incorporate several concepts and ideas from the ancient religion of Zoroastrianism. Scelsi's piece, Uaxuctum, is not a programmatic composition, but it is inspired by certain mythology. The program notes of the recording (Pomarico 2009) state that, "it is based on the legend of the Maya city, Uaxuctum, which was destroyed by its inhabitants for religious reasons." Scelsi's music is extremely effective at painting dark and mysterious atmospheres. Part of the mysterious quality stems from the subconscious connotations of a lost distant civilization. Most of the mysterious qualities arise from the music, which includes dense layers of sustained voices, haunting trills, specific microtonal intervals, and unique instrumentation. The original score of Uaxuctum also calls for instrumental oddities such as a two-hundred liter can and an aluminum hemisphere.

In similar fashion to Uaxuctum, Druj Aeterni examines a once-thriving ancient tradition, all but lost to our modern society. I use some similar compositional techniques to Scelsi, such as multi-layering of several instruments, haunting trills, and the emphasized microtones. Both pieces seek a dark and ethereal sound. Although Scelsi's use of unconventional instruments did not influence my decision to build large custom flexatones, we share the idea of incorporating unconventional instruments.

Some of the notation techniques in Druj Aeterni are influenced by Krzysztof Penderecki's Threnody for the Victims of Hiroshima. In Penderecki's score, he uses

certain symbols to denote specific techniques. For example, the use of " $z$ " placed above 
or on the stem of a note to indicate a fast non-rhythmic tremolo (Penderecki 1990). In Druj Aeterni, I chose to distinguish between tremolos of two strings — for which I utilize the standard triple dash — and single string tremolos, for which I ascribe the "z." Threnody is also a good source for detailed multi-layering techniques. The piece requires 52 string players and Penderecki often composes more than 36 individual voices. During the years that Penderecki composed Threnody, his music was often jarring and fierce. He experimented with dense textures through complex polyphonic writing, and he experimented with notation techniques. Both experimentations influence the score and music of Druj Aeterni. Druj Aeterni weaves a sonic language that lies uniquely between the mystical qualities of Scelsi's music, and the textural densities of Penderecki's music. 


\section{CONCLUSION}

Drawing influence from the styles of two great $20^{\text {th }}$-century composers, Druj Aeterni integrates my interest in Zoroastrianism with my compositional process. The structural organization of the composition relates directly to the caste of Amesha Spenta, Ahura Mazda, and the adversarial Angra Mainyu. The orchestration and timbral organization of Druj Aeterni develop parallel to the structural organization, with the former corresponding to certain aspects of each section's relevant Amesha Spenta.

The compositional elements of the piece - rhythmic motives, pitch schemes, etc. — reflect upon my personal adaptation of Zoroastrianism, as it might apply to ideas founded by modern cosmology and string theory. Our Universe may appear to be finetuned and ordered, but it could be a deceiving pocket of order within a much broader chaos - a vast ocean of innumerable bubble-like universes. Compositionally, Druj Aeterni is highly ordered with elaborate mythological and numerological references. Sonically, however, the piece develops a dark, mysterious, and chaotic atmosphere. 


\section{REFERENCE LIST}

Bode, Dastur Framroza Ardeshir. Songs of Zarathushtra: The Gathas. Translated from the Avesta by multiple sources. London: George Allen \& Unwin LTD, 1952.

Boyce, Mary. Zoroastrians: Their Religious Beliefs and Practices. London: Routledge \& Kegan Paul LTD, 1979.

Cope, David. New Directions in Music. Seventh ed. Long Grove, IL: Waveland Press, Inc., 2001.

Dhalla, Maneckji Nusservanji. Zoroastrian Theology from the Earliest Times to the Present Day. New York: AMS Press, 1972.

Druckman, Jacob. Aureole. New York: Boosey \& Hawkes, Inc., 1979.

Greene, Brian. “The Mystery of the Multiverse.” Newsweek 159, no. 22 (May 28, 2012): 20-25.

Herodotus. The History. Translated by David Grene. Chicago: The University of Chicago Press, 1987.

Nigosian, S. A. The Zoroastrian Faith: Tradition and Modern Research. Montreal: McGillQueen's University Press, 1993.

Penderecki, Krzysztof. Threnody to the Victims of Hiroshima. Miami: Belwin Mills Publishing Corp, 1990.

Pomarico, Emilio, con. Uaxuctum, by Giacinto Scelsi. Bavarian Radio Symphony Orchestra. NEOS 10926, 2009.

Rose, Jenny. Zoroastrianism: A Guide for the Perplexed. New York: Continuum International Publishing Group, 2011. 


\section{APPENDIX}

Figure 1

Overall Form of Druj Aeterni

\begin{tabular}{|c|c|c|c|c|c|}
\hline & $\begin{array}{c}\text { Amesha Spenta's } \\
\text { Title }\end{array}$ & $\begin{array}{c}\text { Abstract } \\
\text { Associations }\end{array}$ & $\begin{array}{c}\text { Element } \\
\text { of Creation }\end{array}$ & $\begin{array}{l}\text { Instrumentation } \\
\text { and Timbre }\end{array}$ & $\begin{array}{c}\text { Approximate } \\
\text { Measures }\end{array}$ \\
\hline 1 & Ahura Mazda & $\begin{array}{l}\text { Omnipotence, } \\
\text { Omniscience, } \\
\text { Omnipresence }\end{array}$ & Universe & $\begin{array}{l}\text { Like an overture of } \\
\text { successive materials, low } \\
\text { rumbling tones in the } \\
\text { electric bass }\end{array}$ & mm. 1-31 \\
\hline 2 & Haurvatat & $\begin{array}{l}\text { Wholeness, } \\
\text { Perfection, } \\
\text { Fulfillment }\end{array}$ & Water & $\begin{array}{l}\text { Tremolo strings, molto } \\
\text { vibrato strings, dense piano } \\
\text { trills, repetitious piano runs }\end{array}$ & mm. 32-65 \\
\hline 3 & Ameretat & $\begin{array}{l}\text { Longevity, } \\
\text { Immortality }\end{array}$ & Plant life & $\begin{array}{l}\text { Flute trills and melodic } \\
\text { fragments, glissandi inside } \\
\text { the piano, fragmented } \\
\text { piano melodies }\end{array}$ & $\mathrm{mm} .60-74$ \\
\hline 4 & Spenta Armaiti & $\begin{array}{l}\text { Holy Devotion, } \\
\text { Guidance }\end{array}$ & $\begin{array}{l}\text { Earth's } \\
\text { Mother }\end{array}$ & $\begin{array}{c}\text { Brass senza sordini, sparse } \\
\text { timpani and crotales } \\
\text { gestures, sparse metallic } \\
\text { percussion }\end{array}$ & mm. 75-97 \\
\hline 5 & Khshathra Vairya & $\begin{array}{l}\text { Desirable } \\
\text { Kingdom, } \\
\text { Sovereignty, } \\
\text { Wealth }\end{array}$ & Metals & $\begin{array}{l}\text { Trumpets with harmon } \\
\text { mutes, metallic percussion, } \\
\text { plucked piano strings, } \\
\text { percussive bass }\end{array}$ & mm. 98-125 \\
\hline 6 & Vohu Manah & $\begin{array}{l}\text { Good Mind, } \\
\text { Shepherd }\end{array}$ & $\begin{array}{l}\text { Animals, } \\
\text { specifically } \\
\text { cattle }\end{array}$ & $\begin{array}{l}\text { Woodwind trills and fast } \\
\text { rhythmic gestures, piano } \\
\text { cluster chords, cowbells, } \\
\text { string pizzicati }\end{array}$ & mm. 126-152 \\
\hline 7 & Asha Vahishta & $\begin{array}{l}\text { Rightesousness, } \\
\text { Cosmic Order }\end{array}$ & $\begin{array}{l}\text { Material } \\
\text { realizations } \\
\text { of } a \text { sha }\end{array}$ & $\begin{array}{c}\text { Muted brass, metallic } \\
\text { percussion, piano pizzicati, } \\
\text { piano and woodwind trills }\end{array}$ & mm. 153-186 \\
\hline 8 & Angra Mainyu & Chaos, Disorder & $\begin{array}{l}\text { Material } \\
\text { realizations } \\
\quad \text { of } d r u j\end{array}$ & $\begin{array}{l}\text { Dense superimpositions of } \\
\text { preceding gestures, chaotic } \\
\text { rapid rhythms }\end{array}$ & mm. 187-215 \\
\hline
\end{tabular}

